UNIVERSIDADE DE BRASÍLIA

KAREN GRAZIELE FURLAN BASSO

SUBSÍDIOS PARA INSERÇÃO DO TURISMO NO ZONEAMENTO ECOLÓGICO ECONÔMICO NO BRASIL

BRASÍLIA

2004 
UNIVERSIDADE DE BRASÍLIA

KAREN GRAZIELE FURLAN BASSO

SUBSÍDIOS PARA INSERÇÃO DO TURISMO NO ZONEAMENTO ECOLÓGICO ECONÔMICO NO BRASIL

BRASÍLIA

2004 
KAREN GRAZIELE FURLAN BASSO

\title{
SUBSÍDIOS PARA INSERÇÃO DO TURISMO NO ZONEAMENTO ECOLÓGICO ECONÔMICO NO BRASIL
}

\author{
Monografia apresentada para obtenção do \\ título de Especialista em Ecoturismo no \\ Curso de Pós-Graduação Latu Senso em \\ Ecoturismo, Centro de Excelência em \\ Turismo, Universidade de Brasília.
}

Orientadora: Prof. Dra. Mônica Veríssimo. 
Basso, Karen Graziele Furlan

Subsídios para Inserção do Turismo no Zoneamento

Ecológico Econômico no Brasil / Karen Graziele Furlan Basso.

$55 \mathrm{f}$.

Monografia (especialização) - Universidade de Brasília. Centro de Excelência em Turismo. Brasília, 2004.

Área de concentração: Turismo

Orientadora: Mônica Veríssimo

1. Turismo 2. Zoneamento Ecológico Econômico 3. Ordenamento Territorial 


\section{AGRADECIMENTOS}

Meus mais sinceros agradecimentos:

A Deus, que tem me conduzido e permitido que tudo ocorresse muito bem até este momento.

A minha família, pelo mais sincero amor, mais sincero zelo; pela esperança que em mim depositam, o consolo; e pelo apoio presente em todos os momentos de minha vida e em todas as minhas escolhas pessoais.

A minha orientadora e professora Mônica Veríssimo, pelo carinho, paciência, dedicação em acompanhar e realizar todas as revisões do estudo, pelo exemplo de dedicação profissional e por estar sempre pronta a ouvir minhas lamentações desesperadas, me mostrando luz quando não via mais nada.

A professora Deise Bezerra, que me ensinou a acreditar no planejamento do Turismo no Brasil.

Aos Professores Sérgio Salvati, André Lima, Lourdes Bandeira e Lucila Egydio, por me apoiarem quando mudei o tema de minha monografia, e estarem sempre à disposição para esclarecimentos e dúvidas.

A Ítalo Mendes, pela sincera amizade, pelas informações, por ter me aconselhado a vir a Brasília e por estar sempre ao meu lado quando solicito.

A Luciana Fonseca (e sua mãe Lúcia), pelo carinho, pela madrugada comigo no hospital, pela casa, pelo computador, pela comida, pelas horas de desabafo, pela amizade.

A Mônica Barcelos, Michele Coelho, Soraya Diniz, Cláudia, Clodoaldo, Plínio, e toda a turma, pela amizade, pelo carinho, pelos conselhos, pelas caronas, pela união, pelos projetos futuros.

A Gustavo Machado, pelo cobertor, pela força, pelo exemplo de persistência e dedicação, e por estar ao meu lado sempre, mesmo quando cheio de trabalho.

Aos meus amigos Leonardo e Gonçalo e todos meus colegas da Antropologia.

A Pedro, por me emprestar o teclado, e a todos os meus colegas do Banco por terem paciência comigo durante estes últimos dias.

A Luciana, Maicira e Moema, minhas irmãs e companheiras de República.

E a todos os amigos e colegas que Brasília me proporcionou e que dividiram comigo mais uma etapa de minha vida.

Peço desculpas se me esqueço de alguém... 
As obras de infra-estrutura não são, em si, causadoras de impactos ambientais e sociais expressivos. Mas induzem processos de desenvolvimento que podem aprofundar as desigualdades sociais e degradar o meio ambiente, comprometendo, inclusive, objetivos econômicos.(...) O uso do ambiente não é obstáculo, mas oportunidade para um desenvolvimento duradouro, sustentável.

\section{Marina Silva}




\section{RESUMO}

BASSO, K. Subsídios para Inserção do Turismo no Zoneamento Ecológico Econômico no Brasil. Setembro, 2004.

O trabalho apresenta subsídios para a elaboração de um modelo referencial do turismo sustentável, tendo por base o ordenamento territorial, a integração das políticas públicas e as questões metodológicas afetas ao instrumento Zoneamento Ecológico Econômico (ZEE). Para isso foram analisadas as políticas publicas em turismo no Brasil, as temáticas propostas nos workshops nacional e regional conduzidos pelo MMA/SDS, bem como o subsídio metodológico de ZEE proposto pelo MMA/SDS, alem de conceitos referentes ao ordenamento territorial da atividade, focalizando a analise sobre a infra-estrutura básica. Como resultado foram geradas algumas considerações acerca da associação do ZEE com outros instrumentos de planejamento do turismo buscando cruzar os dados coletados com o ZEE e a confirmação da importância da integração das políticas públicas no Brasil para a garantia de um turismo sustentável no mesmo.

Palavras-chave: Zoneamento Ecológico Econômico; Ordenamento territorial e ambiental do Turismo; Políticas Públicas em Turismo; Planejamento integrado. 


\begin{abstract}
This work presents subsidies for the elaboration of a referential model of sustainable tourism based on territorial ordering, the integration of public policies and methodological questions on Ecological-Economic Zoning (ZEE). For this, had been analyzed: the public policies about tourism in Brazil, the themes' proposals in national and regional workshops led by Ministry of Environment/ Department of Sustainable Development (MMA/SDS), as well as the methodological subsidy of ZEE proposed by MMA/SDS, besides concepts referred to the territorial ordering of the activity, focusing the analysis on basic infrastructure. As a result, some considerations came out concerning the association of the ZEE with other tourism planning instruments in order to cross data collected with the ZEE and the verification of the importance of the integration of public policies in Brazil to guarantee the practice of sustainable tourism in the country.
\end{abstract}

Keywords: Ecological-Economic Zoning (ZEE); territorial ordering; public policies about tourism in Brazil; integration of public policies. 


\section{LISTA DE ILUSTRAÇÕES}

FIGURA 1 - RESUMO HISTÓRICO DO ZONEAMENTO ECOLÓGICO ECONÔMICO 09

FIGURA 2 - RESUMO HISTÓRICO DAS POLÍTICAS NACIONAIS DE TURISMO 18

FIGURA 3 - SISTEMA DE TURISMO (SISTUR) - MODELO REFERENCIAL DO $\quad 26$

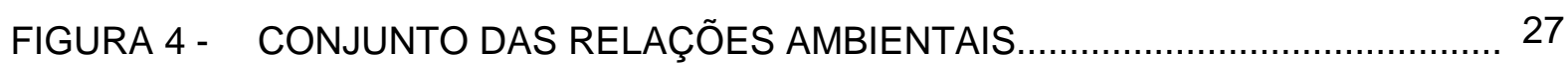

FIGURA 5 - CONJUNTO DA ORGANIZAÇÃO ESTRUTURAL.................................... 27

FIGURA 6 - CONJUNTO DAS AÇÕES OPERACIONAIS ............................................ 28

FIGURA 7 - TEMÁTICAS CORRELATAS AO TURISMO A SEREM CONTEMPLADAS

PELA METODOLOGIA DE ZONEAMENTO - 2004

FIGURA 8 - TEMÁTICAS CORRELATAS AO TURISMO A SEREM

CONTEMPLADAS PELA METODOLOGIA DE ZEE - 2004................... 38

FIGURA 9 - INFRA-ESTRUTURA BÁSICA A SER CONSIDERADA PELO ZEE........... 43

FIGURA 10 - MODELO DE INFRA-ESTRUTURA BÁSICA PARA O ZEE....................... 43

FIGURA 11 DIMENSÕES DOS AMBIENTES NATURAL E HUMANO DO TURISMO

A SEREM CONSIDERADOS PELO ZEE........................................... 44

FIGURA 12 - MODELO DE AÇÃO PARA VIABILIZAR TURISMO SUSTENTÁVEL

DENTRO DO ZEE.

MODELO DE INTEGRAÇÃO DAS UNIDADES TERRITORIAIS E

FIGURA 13 - AMBIENTAIS PARA VIABILIZAR TURISMO SUSTENTÁVEL

DENTRO DO ZEE.. 


\section{LISTA DE ABREVIATURAS E SIGLAS}

\begin{tabular}{|c|c|}
\hline AAE & - Avaliação Ambiental Estratégica \\
\hline APA & - Área de Preservação Ambiental \\
\hline CNTur & - Conselho Nacional de Turismo \\
\hline Combratur & - Comissão Brasileira de Turismo \\
\hline CPRM & $\begin{array}{l}\text { - Companhia de Pesquisas de Recursos Naturais /Serviço } \\
\text { Geológico do Brasil }\end{array}$ \\
\hline EMBRAPA & - Empresa Brasileira de Pesquisas Agropecuária \\
\hline EMBRATUR & - Instituto Brasileiro de Turismo \\
\hline IBAMA & $\begin{array}{l}\text { - Instituto Brasileiro do Meio Ambiente e dos Recursos Naturais } \\
\text { Renováveis }\end{array}$ \\
\hline IBGE & - Fundação Instituto Brasileiro de Geografia e Estatística \\
\hline INPE & - Instituto Nacional de Pesquisas Espaciais \\
\hline MMA & - Ministério do Meio Ambiente \\
\hline Mtur & - Ministério de Turismo \\
\hline PAEG & - Plano de Ação Econômica \\
\hline Plantur & - Plano Nacional de Turismo \\
\hline PIB & - Produto Interno Bruto \\
\hline PNT & - Política Nacional de Turismo \\
\hline SAE/PR & $\begin{array}{l}\text { - Secretaria de Assuntos Estratégicos ligada a Presidência da } \\
\text { Republica }\end{array}$ \\
\hline SDS & - Secretaria de Desenvolvimento Sustentável \\
\hline SIG & - Sistema de Informações Geográficas \\
\hline SISTUR & - Sistema de Turismo \\
\hline ZEE & - Zoneamento Ecológico Econômico \\
\hline
\end{tabular}




\section{SUMÁRIO}

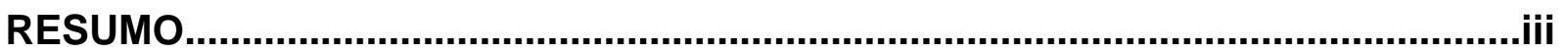

ABSTRACT............................................................................................................ iv

LISTA DE ILUSTRACOES...............................................................................

LISTA DE ABREVIATURAS E SIGLAS................................................................vi

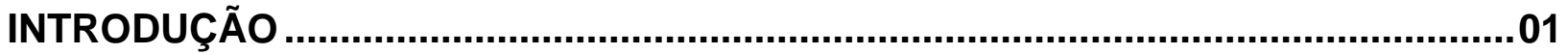

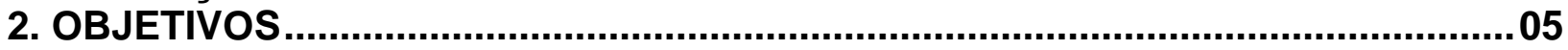

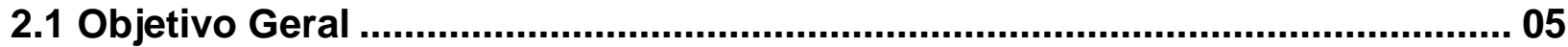

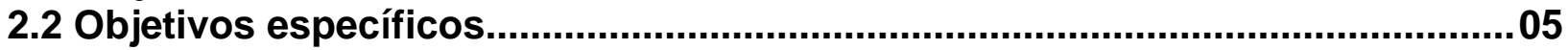

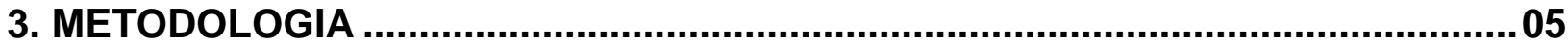

4. O INSTRUMENTO ZONEAMENTO ECOLÓGICO ECONÔMICO NO BRASIL ........07

4.1Finalidade do instrumento ................................................................................. 07

4.2 O ZEE no Brasil: histórico ............................................................................. 08

4.3 Estado atual do Zoneamento Ecológico Econômico no Brasil ..........................11

4.3.1 Diretrizes para o Projeto ZEE Brasil ..............................................................13

4.3.2 Temáticas de interesse das regiões brasileiras para constarem dentro do ZEE.................................................................................................................16

4.3.3. Problemas metodológicos do ZEE afetos ao turismo...................................17

5. PANORAMA DO TURISMO NO BRASIL ..........................................................17

5.1 Políticas públicas em turismo no Brasil.........................................................17

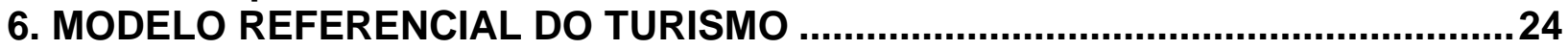

6.1 Sistema de Turismo .........................................................................................24

7. MODELO REFERENCIAL PARA TURISMO SUSTENTÁVEL DENTRO DO ZEE .. 29

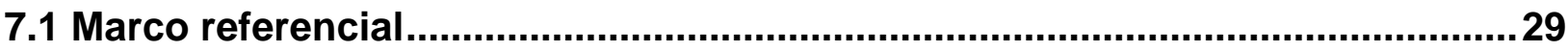

7.1.1 Desenvolvimento sustentável .....................................................................29

7.1.2 Visão Sistêmica .................................................................................................29

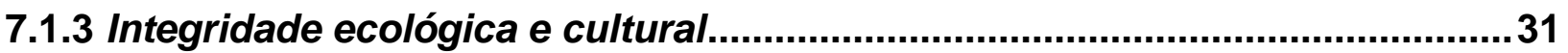

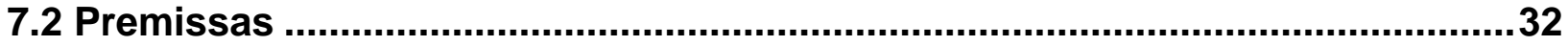

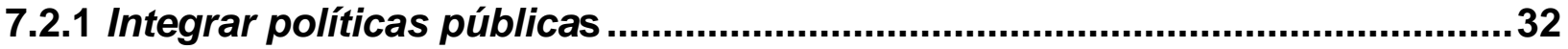

7.2.2 Utilizar unidades territoriais e ambientais .................................................. 33

7.2.3 Tratamento integrado das questões urbanas, rurais e de manutenção dos sistemas naturais.........................................................................................34

7.30 turismo dentro das temáticas e metodologia do programa ZEE....................34

7.3.1 O turismo dentro das temáticas prioritárias do programa ZEE: modelo 1 ...34

7.3.2 O turismo dentro das temáticas prioritárias do programa ZEE: modelo 2 ... 37

7.4.Modelo referencial do turismo como base para elaborar modelo referencial para turismo sustentável dentro do ZEE..............................................................42

7.4.1 Infra estrutura para o turismo dentro do ZEE ..............................................42

7.4.2 Dimensões do ambiente natural e humano dentro do ZEE ...........................44

7.4.3 Modelo de ação para viabilizar turismo sustentável dentro do ZEE...............45

7.4.4. Modelo de integração das unidades territoriais e ambientais para viabilizar turismo sustentável dentro do ZEE..............................................................46

CONCLUSÃO

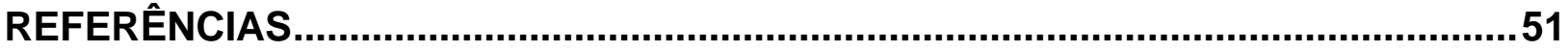




\section{INTRODUÇÃO}

O Turismo é uma atividade que se consolidou no século XX, e está adquirindo proporções cada vez maiores dentro da conjuntura atual, marcada pela mundialização. No Brasil, a atividade está no auge de seu desenvolvimento e sucesso. Tendo em vista que ela interfere e exerce influências econômicas, sociais, culturais e ambientais sobre determinado território, dentro dos princípios da sustentabilidade, conclui-se que a atividade turística depende diretamente do ordenamento territorial. Neste caso, podese dizer, em parte, que o sucesso do turismo depende da efetividade do instrumento de Zoneamento Ecológico-Econômico (ZEE), cujo objetivo principal é "contribuir para que o ordenamento territorial e ambiental seja realizado de forma integrada, com parâmetros mais sustentáveis no uso dos recursos naturais e de maneira mais solidária e ética no tratamento dos espaços humanos" (VERíSSIMO, 2003, p. 456).

A política nacional de turismo no Brasil passou por vários períodos. Entre os anos de 1938 a 1957, a política do turismo ficou restrita a diplomas legais que regulamentavam venda de passagens aéreas, terrestres ou marítimas e as agências de viagem e turismo. A partir de 1958, a prioridade foi transferida para a ampliação e modernização do parque hoteleiro do país. Em 1991, porém, o governo federal passou a considerar o ordenamento territorial como condição básica para buscar atender ao amplo e complexo espaço que a atividade utiliza, ao invés de priorizar a questão hoteleira. Contudo, devido ao tratamento superficial da questão territorial, esta ficou apenas como citação dentro dos diversos diplomas legais que vieram em seguida.

Em 1991, enquanto o ordenamento territorial era apenas uma retórica dentro da política do turismo, começam os trabalhos de Zoneamento Ecológico-Econômicos, sob a coordenação geral da Secretaria de Assuntos Estratégicos, ligada à Presidência da República (SAE/PR). Durante dez anos, foram elaborados diversos ZEE's em todo o Brasil. Mas com a extinção da SAE/PR, a responsabilidade pela coordenação e execução do ZEE foi transferida ao Ministério do Meio Ambiente (MMA). Em 2001, como forma de elaborar um diagnóstico, avaliação e perspectivas da situação do Programa ZEE no Brasil, foram realizados sete workshops (sendo dois nacionais e cinco regionais). Entre os problemas detectados nos encontros, destaca-se a impossibilidade de compreensão ampla da realidade nacional através dos inúmeros ZEE's elaborados. Permanecia o isolamento e a divisão das questões territoriais em 
setores sem articulação com o sistema de planejamento. E dentre as temáticas consideradas prioritárias, o turismo aparece como uma questão a ser incluída no processo de elaboração do Zoneamento.

As diversas contribuições dos estados durante os workshops levaram o MMA (através da Secretaria de Desenvolvimento Sustentável - SDS) a propor uma estrutura geral do Programa ZEE, com indicativo de diretrizes metodológicas básicas para a elaboração desse instrumento no território nacional. O documento intitulado Diretrizes metodológicas para o Zoneamento Ecológico-Econômico (MMA/SDS, 2001) apresenta a concepção geral, os arranjos institucionais, os fundamentos conceituais e as diretrizes para os procedimentos operacionais necessários à execução do ZEE. Contudo, do ponto de vista técnico e político, foram poucos os avanços na condução do mesmo. Em termos metodológicos, não fica claro no documento como deve ser a avaliação do uso do território, considerando a necessidade de integração das políticas públicas e do ordenamento territorial e ambiental (VERÍSSIMO, 2003, p. 43). E como instrumento político, o ZEE depende da superação da fragmentação no contexto do processo de planejamento $^{1}$ e de formulação de políticas públicas. Ou seja,

\footnotetext{
${ }^{1}$ Planejamento = planejar consiste analisar uma realidade e condicionar as ações ao problema, sendo um processo sistemático e flexível de prevenção do rumo dos acontecimentos. Considerado como trabalho de preparação e elaboração por etapas, com bases técnicas, de políticas, planos, programas e projetos com objetivos definidos, na lição de Eros Roberto GRAU (1983. p.2), "é o planejamento que procura ordenar, sob o ângulo macroeconômico, o processo econômico, para melhor funcionamento da ordem social em condições de mercado". Ele não é um fim em si mesmo e sim um meio para trazer mudanças quantitativas e qualitativas. Envolve riscos, pois planejar sem ter claro o objetivo que se pretende alcançar traz como conseqüência a maximização dos problemas (MOLINA, 2001, p. 60-62). Neste sentido, o planejamento deve ser compreendido e analisado em seu contexto como um fator dinâmico, estando estritamente relacionado com as características do meio onde se pretende executá-lo. Planejar demanda um tempo determinado, que pode variar muito de acordo com o objeto analisado, podendo ser de curto, médio e longo prazo. As informações se divergem no que diz respeito à determinação destes prazos dentro do planejamento. Para este trabalho (considerando o tema em questão e a análise pratica do planejamento nacional, em seu sentido macro), considero como prazo mínimo ideal o período de dez anos, acreditando na impossibilidade de se alcançar e medir resultados que englobem sua complexidade e seu grau de integração com o meio ambiente em período inferior a este.

Planejamento do turismo $=0$ planejamento turístico pode ser conceituado como ação intervencionista que, por instrumentos legais próprios, visa ordenar o patrimônio turístico, os investimentos setoriais, a qualidade dos serviços e 0 incremento do consumo. Segundo FERRAZ (1992, 54-59), no turismo brasileiro a intervenção estatal vem ocorrendo sistematicamente sob as modalidades de indução e controle e, esporadicamente, sob a de participação. Há normas intervencionistas de controle sobre uso e ocupação dos atrativos naturais e culturais e sobre a produção de serviços turísticos e existem normas de indução para investimentos no setor e para ampliação do consumo dos serviços turísticos. Normalmente na etapa de elaboração de planos de turismo, a percepção do futuro é realizada por meio de métodos de prognóstico, o que o torna extremamente frágil, considerando que em muitas ocasiões os métodos se baseiam em informação manipulada. Deste modo, é muito arriscado estabelecer estratégias para alcançar um determinado estágio futuro, do que decorre que o planejamento do turismo se encontra orientado para o gigantismo e posterior atrofiamento do sistema provocando seu colapso. Ao elaborar uma imagem do futuro o planejamento mostra tendências deterministas e probabilistas. Resulta imprescindível que o sistema seja objeto de estudo como um todo e que se afete como tal nos momentos das decisões e da atuação.Nesse sentido, configura-se o Zoneamento Ecológico-Econômico um importante instrumento para o planejamento da atividade como um todo, principalmente no que tange ao ordenamento territorial.
} 
depende de uma complexa articulação político-institucional no processo de tomada de decisão, como forma de integrar os domínios econômicos, sociais e ambientais no território.

Como se observa existem entraves técnicos e políticos para a condução do ZEE e, por conseguinte, a interface da atividade turística ainda não foi contemplada pelo instrumento. O máximo que se obteve neste sentido foram workshops celebrados pelos Ministérios do Turismo e do Meio Ambiente para a elaboração das diretrizes preliminares para criação de uma "Agenda ambiental para o turismo", que teve início em março de 2004 e até o momento não foi oficialmente publicada. No documento preliminar aparece o instrumento ZEE como uma das interfaces importantes a ser considerada nas ações de ambos os Ministérios.

Mas se por um lado existem entraves técnicos e políticos para condução do ZEE e, por conseguinte, para a inserção da atividade turística, por outro existem equívocos entre planejamento turístico e políticas de turismo, e confusão em considerar políticas urbanas, que são fundamentais para diversas atividades, entre elas turismo, como sendo políticas do turismo. Como resultado, existe a ineficiência tanto de políticas quanto de planos para esse setor e a certeza da total dependência de demais políticas públicas para o sucesso da atividade turística. Isso fica claro quando se observa que as conquistas para o Turismo no Brasil ficam quase que relegadas às ações parciais, que na maioria das vezes são direcionadas à questão hoteleira e/ou para embasar financiamentos e linhas de créditos para o setor.

Pelo exposto, este trabalho visa contribuir para ampliar o processo de integração do planejamento, formulação de políticas públicas e articulações político-institucionais, tendo a atividade turística como ponto focal. O ZEE será o instrumento de análise porque visa o ordenamento territorial, que é a expressão das políticas econômicas, sociais, culturais e ecológicas integradas, as quais são a base do turismo sustentável.

O trabalho é dividido em quatro partes. A primeira consiste da revisão bibliográfica sobre origem, finalidades e características do instrumento ZEE, bem 
como mostra as demandas temáticas e metodológicas dos estados brasileiros dentro do atual Programa ZEE, a partir da análise realizada por VERÍSSIMO (2003). A segunda parte apresenta um histórico e uma avaliação da política nacional do turismo. A terceira exibe de forma sucinta o modelo referencial teórico do turismo de Mário Carlos BENI (2001) desenvolvido sob o enfoque da Teoria Sistêmica. A quarta parte consiste da elaboração de diretrizes para construção de um Modelo Referencial do Turismo Sustentável para ZEE.

A construção do Modelo Referencial do Turismo Sustentável para ZEE foi baseada a partir do marco referencial e das premissas definidas na tese de VERÍSSIMO (2003) e do Modelo Referencial de BENI (2001).

Os marcos referenciais utilizados para a construção do Modelo foram: desenvolvimento sustentável; visão sistêmica; integridade ecológica e cultural; e participação. As premissas foram: adoção integrada das políticas públicas; utilização simultânea das unidades territoriais e ambientais do ZEE; tratamento integrado das questões urbanas, rurais e manutenção dos sistemas naturais. Através destes, foi possível inserir o tema turismo dentro das temáticas prioritárias do programa ZEE.

Em seguida, foi utilizado o modelo referencial do turismo de BENI (2001), com ênfase na infra-estrutura -, para elaborar um modelo referencial de turismo sustentável a ser inserido no ZEE. Foram definidos os temas de interesse para o turismo e o ZEE no que diz respeito à infra-estrutura. O enfoque dado a esta questão - infra-estrutura - em oposição a outras de extrema importância para a atividade (como atrativos turísticos, por exemplo) foi aleatório, buscando prioritariamente aplicar a metodologia.

A parte final do capítulo apresenta as conclusões sobre o que enfocar no: planejamento, para que o turismo seja visto no longo prazo; nas políticas públicas, para que a atividade seja sustentável; e no ZEE, para que o ordenamento territorial e as questões ambientais relativas ao turismo sejam contemplados pelo instrumento. 


\section{OBJETIVOS}

\subsection{Objetivo geral}

Subsidiar a elaboração do instrumento Zoneamento Ecológico-Econômico (ZEE) a partir das demandas da atividade turística.

\subsection{Objetivos específicos}

- Apresentar panorama do Turismo no Brasil com enfoque no seu planejamento, nas suas políticas públicas e nos equívocos de implementação dessa atividade;

- Elaborar diretrizes para construção de um modelo referencial do turismo sustentável voltado para o Zoneamento Ecológico-Econômico (ZEE).

\section{METODOLOGIA}

O trabalho de pesquisa foi desenvolvido envolvendo quatro etapas. A primeira consistiu na elaboração e planejamento do projeto, e na coleta de dados. Foram coletados ${ }^{2}$ livros, cds, revistas, leis, decretos, artigos científicos e teses, entre estes os resultados dos workshops e as Diretrizes para elaboração de ZEE publicados pelo MMA; alguns relatórios de ZEEs já elaborados e/ou em fase de elaboração como o ZEE do Baixo Rio Parnaíba; a tese de doutorado de Mônica Veríssimo, Metodologia de Zoneamento Ambiental, desenvolvida tendo como área de estudo a Área de Preservação Ambiental (APA) Gama Cabeça-deVeado - Distrito Federal; além de um apanhado de documentos publicados pelo Instituto Brasileiro de Turismo (EMBRATUR).

A segunda etapa consistiu na análise dos dados e revisão bibliográfica sobre origem, finalidades e características do instrumento ZEE, no que levou a necessidade de apresentar as demandas temáticas e metodológicas dos estados brasileiros dentro do atual Programa. O principal objetivo nesta etapa foi verificar todas as finalidades que se atribuem ao instrumento ZEE e o porquê dele não ser

\footnotetext{
${ }^{2}$ Com o auxilio fundamental de Mônica Veríssimo que não só me orientou em todo este processo, como confiou -me documentos imprescindíveis para esta pesquisa.
} 
largamente utilizado no Brasil. Em dez anos de ZEE (1991-2001) o MMA/SDS constatou que apenas $11 \%$ do país tinha efetivado o ZEE. Nesse caso, era importante verificar por quais motivos o instrumento foi tão pouco utilizado. Outros pontos levantados foram as demandas temáticas e metodológicas atuais a serem contempladas pelo Programa ZEE. A questão do ordenamento territorial e as questões ambientais foram a base para análise do turismo neste trabalho. Para essa parte, o documento de referência foi uma tese de doutorado (VERÍSSIMO, 2003).

Por outro lado, num terceiro momento, foram analisadas todas as publicações e dados encontrados com referência a história das políticas públicas do turismo no Brasil com objetivo de verificar ações direcionadas à questão ambiental e de ordenamento territorial; e verificar prioridades das políticas públicas buscando definir um perfil das mesmas até o momento atual. Entre os documentos que embasaram esta pesquisa, o livro de Cássia CRUZ (2001) se destaca devido à definição, pela autora, de três momentos na história das políticas, apresentados no decorrer desta monografia. Alguns dos pontos analisados foram: falta de clareza e abordagem limitadas em relação aos aspectos do turismo; dificuldade de integrar políticas; e a atenção que é dada na infra-estrutura urbana. A partir deste contexto, buscou-se verificar como a questão ambiental e o ordenamento territorial do turismo são vistos ao longo dos anos. Esta etapa termina com a apresentação do referencial teórico do turismo no que concerne à Teoria Sistêmica. Para esta abordagem, foram tomadas como base publicações de Mário Carlos $\mathrm{BENI}^{3}$, que definem um Modelo Referencial do Turismo no Brasil.

A quarta etapa tratou da elaboração de diretrizes para construção de um Modelo Referencial para o Turismo Sustentável. Para a construção dessas diretrizes foram considerados, de um lado, o resultado das análises realizadas em torno da

\footnotetext{
${ }^{3}$ BENI, Mário Carlos. Análise estrutural do turismo. 4.ed. rev. São Paulo: SENAC, 2001.

Política e Estratégia do desenvolvimento regional. Planejamento integrado e sustentável do turismo, Turismo em Análise, 1999, Vol.10, No. 1, pp. 7- 17

Política e estratégia do desenvolvimento regional: roteiro metodológico com base na instrumentação e operacionalização do SISTUR (Sistema de Turismo aplicado ao projeto costa oeste-Estudo de caso), Turismo: visão e ação, Ano 2, No. 3. 1999, pp, 51-70
} 
temática de ZEE (segunda etapa da pesquisa); e do outro, o resultado das análises sobre as políticas federais de turismo e seu Modelo Referencial (BENI, 2001). Apresentando os elementos e diferentes variáveis do sistema de turismo, buscou-se direcionar a análise para a infra-estrutura tendo em vista a constatação das ações governamentais neste sentido. Para esta parte, foram definidos os itens de infra-estrutura que têm relação direta com o ordenamento territorial, uma vez que esta é a tônica do instrumento ZEE.

Contrapondo-se as duas etapas anteriores (segunda e terceira) e definindo as demandas de turismo em relação ao ZEE, buscou-se elaborar o Modelo, considerando os princípios básicos que norteiam as metodologias de Zoneamento; as Diretrizes metodológicas para ZEE do MMA/SDS (2001); as lacunas temáticas e metodológicas dos workshops nacional e regional ocorridos sobre o ZEE; a metodologia de Zoneamento Ambiental (VERÍSSIMO, 2003); e a metodologia de turismo (BENI, 2001).

\section{O INSTRUMENTO ZONEAMENTO ECOLÓGICO-ECONÔMICO NO BRASIL}

\subsection{Finalidade do instrumento}

O Zoneamento Ecológico-Econômico, também chamado de Zoneamento Ambiental (ZA), visa subsidiar as políticas públicas de planejamento e gestão urbana, rural e das áreas preservadas/protegidas. Segundo BECKER (1996, 181-193), a finalidade do ZEE é dotar o Governo das bases técnicas para espacialização das políticas públicas visando o ordenamento territorial. Por sua vez, "a ordenação do território é entendida como expressão espacial das políticas econômicas, social, cultural e ecológica." (BECKER, 1996, 189) Observa-se, portanto, que o Zoneamento Ecológico-Econômico (ZEE) é um instrumento técnico e político de planejamento, que oferece informações ao poder público e demais setores e representações, através de levantamentos de dados físicos, socioeconômicos e culturais de um dado território, constituindo um diagnóstico onde são assinaladas regras de uso e ocupação do espaço. Ao mesmo tempo, visando compatibilizar o crescimento econômico e a proteção dos recursos naturais e biodiversidade, o ZEE 
tem o papel de dividir o território em zonas, de acordo com as necessidades de conservação e recuperação natural e com os princípios do desenvolvimento sustentável.

\begin{abstract}
"Abaixo, de forma resumida, as principais finalidades do instrumento ZEE: Instrumento técnico e político de planejamento; Instrumento para racionalizar a ocupação dos espaços e redirecionar as atividades; Subsídio às estratégias e ações para elaborar e executar planos regionais em busca do desenvolvimento sustentável; Primeira etapa do processo de planejamento, destinada a diagnosticar e configurar estratégia de planejamento global, assinalando regras; Instrumento que visa otimizar os usos dos espaços e políticas públicas; Instrumento para dotar o Governo das bases técnicas para espacializar as políticas públicas, visando ordenação territorial; Instrumento para propor ordenamento que possibilite subsidiar políticas públicas de planejamentos governamentais, voltadas às estratégias de desenvolvimento regional; Instrumento que visa compatibilizar interesses econômicos, melhoria das condições sociais das populações, conservação e manejo dos recursos naturais e gerenciamento responsável do território." (VERISSIMO, 2003:13)
\end{abstract}

\title{
4.2. O ZEE no Brasil: histórico
}

A história do ZEE no Brasil tem início em 1981, com sua citação compondo um dos instrumentos de planejamento ambiental apresentado pela Política Nacional de Meio Ambiente (Lei n. 6.938, de 31/08/81). Porém, o interesse pelo Zoneamento Ecológico-Econômico do território cresce apenas na década de 90, quando foram criados o Programa de Zoneamento Ecológico Econômico do Território Nacional (PZEE), a Comissão Coordenadora do Zoneamento Ecológico Econômico do Território Nacional - CCZEE (Decreto $n^{0}$ 99.540/90) e o Grupo de Trabalho para orientar a execução do ZEE (Decreto $n^{\circ}$ 99.193/90).

Atualmente, os trabalhos de Zoneamento são executados basicamente pelos estados, a depender de seu interesse. A coordenação dos programas de ZEE foi alterada. A SAE/PR foi extinta, transferindo a atribuição do ZEE para o Ministério do Meio Ambiente (Medida Provisória $n^{0}$ 1.911/99). A Secretaria de Políticas para o Desenvolvimento Sustentável (SDS) é a responsável por coordenar o ZEE no território brasileiro. 
Com o objetivo de formular um programa de ações compartilhadas, a SDS lançou uma estrutura geral para o ZEE no Brasil ${ }^{4}$, como início de um processo de articulação institucional, criando um consórcio entre instituições denominado Consórcio ZEE/Brasil. A princípio, fazem parte desse consórcio: a Secretaria de Políticas para o Desenvolvimento Sustentável (SDS); o Instituto Brasileiro do Meio Ambiente e dos Recursos Naturais Renováveis (IBAMA); a Companhia de Pesquisas de Recursos Naturais - Serviço Geológico do Brasil (CPRM); a Empresa Brasileira de Pesquisas Agropecuária (EMBRAPA); o Instituto Nacional de Pesquisas Espaciais (INPE); e a Fundação Instituto Brasileiro de Geografia e Estatística (IBGE).

De forma resumida, é apresentado em seguido um quadro com um resumo histórico do ZEE no Brasil. (Figura 1)

FIGURA 1 - RESUMO HISTÓRICO DO ZONEAMENTO ECOLÓGICO ECONÔMICO NO BRASIL $(1981-2000)$

\begin{tabular}{|c|c|}
\hline \multicolumn{2}{|r|}{ HISTÓRICO DO ZONEAMENTO AMBIENTAL NO BRASIL } \\
\hline Ano & Observações \\
\hline 1981 & $\begin{array}{l}\text { O Zoneamento Ambiental surge no Brasil como um dos instrumentos de planejamento ambiental inscrito na Política } \\
\text { Nacional de Meio Ambiente (Lei } n^{0} 6.938 \text {, de } 31 / 08 / 81 \text { - artigo } 9^{0} \text { inciso II). }\end{array}$ \\
\hline $\begin{array}{c}1981 \text { a } \\
1988\end{array}$ & $\begin{array}{l}\text { O termo Zoneamento passa a ser empregado para trabalhos que contemplavam o ambiente natural de um lado, e as } \\
\text { atividades humanas de outro. }\end{array}$ \\
\hline 1988 & $\begin{array}{l}\text { Início dos trabalhos de Zoneamento Ambiental no Brasil, dentro de uma escala mais regional. O Programa Nossa } \\
\text { Natureza (1988), criado pelo Decreto } n^{0} 96.044 \text {, de } 12 / 10 / 88 \text {, sugere que os trabalhos de Zoneamento Ambiental } \\
\text { deveriam ser conduzidos para todo o Território Nacional. O objetivo dessa proposta era conter a ocupação desordenada } \\
\text { do território nacional e os prejuízos dela decorrentes. Adota-se o termo Zoneamento Ecológico-Econômico - ZEE } \\
\text { para distinguir dos demais Zoneamentos Ambientais que estavam sendo conduzidos no Brasil. Foi com base no } \\
\text { Programa Nossa Natureza, e alguns trabalhos realizados no exterior e no país, que se iniciou a discussão da base } \\
\text { conceitual do chamado Zoneamento Ecológico-Econômico - ZEE. }\end{array}$ \\
\hline 1990 & $\begin{array}{l}\text { Criação do Programa de ZEE do Território Nacional (PZEE) e do Grupo de trabalho para orientar a execução do ZEE } \\
\text { (Decreto 99.193/90); } \\
\text { Criação da Comissão Coordenadora do ZEE do Território Nacional (CCZEE, 1990), instituída pelo Decreto nº } 99.540 \text { de } \\
\text { 21/09/90. }\end{array}$ \\
\hline 1991 & Criação do Programa de Zoneamento para Amazônia Legal - PZEEAL. \\
\hline $\begin{array}{c}1992 \text { a } \\
1998\end{array}$ & $\begin{array}{l}\text { Elaboração de Zoneamentos pelos Estados, a depender dos seus interesses, seja em termos de parcerias, seja ao nível } \\
\text { de coordenação e/ou execução dos trabalhos. }\end{array}$ \\
\hline 1998 & $\begin{array}{l}\text { Fortalecimentos dos Zoneamentos através do Banco Mundial (PPG7) que, liberando recursos para este fim, atribuiu a } \\
\text { sua execução aos Estados. }\end{array}$ \\
\hline 1999 & $\begin{array}{l}\text { Extinção da SAE/PR (Medida Provisória n0 1911-8/99 de 29/07/99, Art. 19, inciso XI); Transferência das atribuições do } \\
\text { ZEE para o Ministério do Meio Ambiente (Medida Provisória n } 1911 \text { - 8/99 de 29/07/99, Art. 14, inciso XII, item f, que } \\
\text { dispõe sobre a organização da Presidência da República e dos Ministérios e atualizada pela Medida Provisória nº } 1999 \text { - } \\
13 \text { de 14/12/99). Alocação do ZEE dentro da Secretaria de Políticas para o Desenvolvimento Sustentável - SDS. }\end{array}$ \\
\hline 2000 & Inclusão do ZEE no Plano Plurianual do Governo Federal para período 2000 - 2003 \\
\hline
\end{tabular}

4 PROGRAMA ZONEAMENTO ECOLÓGICO ECONÔMICO - Diretrizes metodológicas para o zoneamento ecológico econômico do Brasil. - Brasília: MMA/SDS, 2001. 110p. 
Em 2002, o Presidente Fernando Henrique Cardoso, através do decreto $\mathrm{n}^{0}$ 4.297, de 10 de julho de 2002, regulamenta o art. 9, inciso II, da Lei no 6.938, de 31 de agosto de 1981, estabelecendo critérios para o Zoneamento EcológicoEconômico do Brasil - ZEE, quais sejam:

Art. $2^{\circ} O$ ZEE, instrumento de organização do território a ser obrigatoriamente seguido na implantação de planos, obras e atividades públicas e privadas, estabelece medidas e padrões de proteção ambiental destinados a assegurar a qualidade ambiental, dos recursos hídricos e do solo e a conservação da biodiversidade, garantindo o desenvolvimento sustentável e a melhoria das condições de vida da população.

Art. $3^{\circ}$ O ZEE tem por objetivo geral organizar, de forma vinculada, as decisões dos agentes públicos e privados quanto a planos, programas, projetos e atividades que, direta ou indiretamente, utilizem recursos naturais, assegurando a plena manutenção do capital e dos serviços ambientais dos ecossistemas.

Parágrafo único. $O$ ZEE, na distribuição espacial das atividades econômicas, levará em conta a importância ecológica, as limitações e as fragilidades dos ecossistemas, estabelecendo vedações, restrições e alternativas de exploração do território e determinando, quando for o caso, inclusive a relocalização de atividades incompatíveis com suas diretrizes gerais.

Segundo o Decreto n. 4.297/02:

Art. $4^{\circ} \mathrm{O}$ processo de elaboração e implementação do ZEE:

I - buscará a sustentabilidade ecológica, econômica e social, com vistas a compatibilizar o crescimento econômico e a proteção dos recursos naturais, em favor das presentes e futuras gerações, em decorrência do reconhecimento de valor intrínseco à biodiversidade e a seus componentes;

II - contará com ampla participação democrática, compartilhando suas ações e responsabilidades entre os diferentes níveis da administração pública e da sociedade civil; e

III - valorizará o conhecimento científico multidisciplinar.

Em termos de conteúdo, fica definido que:

Art. 11. O ZEE dividirá o território em zonas, de acordo com as necessidades de proteção, conservação e recuperação dos recursos naturais e do desenvolvimento sustentável.

Parágrafo único. A instituição de zonas orientar-se-á pelos princípios da utilidade e da simplicidade, de modo a facilitar a implementação de seus 
limites e restrições pelo Poder Público, bem como sua compreensão pelos cidadãos.

Ainda conforme Decreto n. 4.297/02, a definição de cada zona deve obrigatoriamente observar:

\begin{abstract}
I - um diagnóstico dos recursos naturais, da socioeconômia e do marco jurídico-institucional, com itens como: unidades dos sistemas ambientais, potencialidade e fragilidade natural potencial, indicação de corredores ecológicos potenciais e efetivos, tendências de ocupação e articulação regional, condições de vida da população, incompatibilidades legais e áreas institucionais.

II - informações constantes do Sistema de Informações Geográficas, gerando produtos em escala 1:250.000 ou maiores e reunindo-as e compatibilizando-as em um único banco de dados.

III - cenários tendenciais e alternativos.

IV - diretrizes gerais e específicas, contendo obrigatoriamente: atividades adequadas a cada zona e os critérios orientadores de cada uma delas; necessidades de proteção ambiental e conservação das águas, do solo, do subsolo, da fauna e flora e demais recursos naturais renováveis e nãorenováveis; definição de áreas para unidades de conservação; medidas destinadas a promover, de forma ordenada e integrada, o desenvolvimento ecológico e economicamente sustentável; medidas de controle e de ajustamento de planos de zoneamento de atividades econômicas e sociais resultantes da iniciativa dos municípios; planos, programas e projetos do governo federal, estadual e municipal; bem como suas respectivas fontes de recursos, dentre outros.
\end{abstract}

\title{
4.3. Estado atual do Zoneamento Ecológico-Econômico no Brasil
}

Após a extinção da SAE/PR, a responsabilidade pela coordenação e execução do ZEE passou para o MMA, através da Secretaria de Política para o Desenvolvimento Sustentável (MMA/SDS). Como medida inicial, a SDS decidiu elaborar um diagnóstico da situação do Programa ZEE. Assim, em junho de 2000, foram apresentadas as experiências de ZEE's, executados à época da coordenação da SAE-PR. Inicialmente foi realizado o workshop "Dez anos do Programa Zoneamento Ecológico-Econômico no Brasil: Avaliação e perspectivas". Os objetivos do encontro foram:

- Recuperar as informações dos trabalhos de Zoneamento no país;

- Avaliar a situação atual do Zoneamento no país;

- Definir tendências;

- Integrar os participantes;

- Inserir o Programa no processo de planejamento; 
- Dar visibilidade junto aos tomadores de decisão;

- Divulgar os trabalhos já realizados;

- Incentivar os estados a fortalecer os programas estaduais;

- Apresentar o Projeto ZEE Brasil elaborado pela SDS/MMA;

- Formar a rede ZEE.

Através de uma análise dos produtos de ZEE pelos estados e da condução do processo de Zoneamento no Brasil, desde sua implantação, foram detectados problemas, os quais foram apontados pelo SDS/MMA, na ocasião do encontro, quais sejam:

- O programa gerou uma série de ZEE's regionais fracionados e dispersos, utilizando metodologias diversificadas, o que impossibilita uma compreensão ampla da realidade nacional, ou seja:

- ZEE parciais em áreas escolhidas por critérios os mais variados, sem uniformização;

- Descontinuidade e sobreposição de áreas;

- Diferentes metodologias: SAE-PR/MMA, PRODEAGRO, IBGE, PANTANAL, EMBRAPA;

- Estudos realizados em diferentes épocas ao longo de 10 anos com impossibilidade de compará-lo;

- Perda de dados por caducidade, extravio e falta de divulgação;

- Grande quantidade de dados não digitalizados;

- Isolamento e setorização, sem articulação com o sistema de planejamento.

- Não havia disponível um Zoneamento em escala compatível com as necessidades do planejamento do Governo Federal. Verificou-se existir apenas dois macro-diagnósticos referentes à Amazônia Legal e à Zona Costeira além de uma dispersa base pré-existente e dados temáticos; 
- Dificuldade de acesso aos dados existentes;

- Desarticulação entre executores e fontes de financiamento

Em seguida, foram realizados cinco workshops regionais e mais um nacional para verificar os problemas e as demandas sobre o ZEE. Como resultado foi publicado um documento para servir de base para os trabalhos de ZEE, intitulado Diretrizes Metodológicas para o ZEE do Brasil. Este documento apresenta a estrutura geral do Programa, delineando a concepção geral, os arranjos institucionais, os fundamentos conceituais e as diretrizes para os procedimentos operacionais metodológicos básicos para a elaboração do ZEE no território nacional.

Ainda segundo o documento, o programa ZEE terá, a princípio, duas dimensões: o Projeto ZEE Brasil, com visão nacional, e os Projetos de ZEE's regionais e estaduais. Apesar dos produtos serem em escalas diferentes, a idéia é existir correlação e complementação de informações. O ZEE será executado através de quatro fases de trabalho que abrangem: Planejamento do Projeto; Diagnóstico

\section{Ambiental; Prognóstico; e Implementação.}

Para a fase de Planejamento foi elaborada uma proposta das diretrizes metodológicas básicas de ZEE, pelo MMA/SDS. O documento correspondente é Diretrizes metodológicas para o Zoneamento Ecológico-Econômico. Este se constitui ponto de partida para orientar articulações político-institucionais necessárias a sua viabilização, identificar as demandas técnicas, financeiras, institucionais e sociais, mobilizar os recursos financeiros e humanos indispensáveis à execução do Zoneamento.

A seguir serão apresentadas as diretrizes para o projeto ZEE Brasil ${ }^{5}$, de maneira resumida, segundo VERÍSSIMO (2003, p. 33 a 35).

\subsubsection{Diretrizes para o projeto ZEE Brasil}

A. Aspectos conceituais :

- O ZEE Brasil deve enfrentar o desafio conceitual de superar a contradição desenvolvimento-meio ambiente, articulando, em termos metodológicos e

\footnotetext{
${ }^{5}$ Este material é resumo elaborado por VERÍSSIMO (2003) do documento"Diretrizes metodológicas para ZEE (MMA, SDS,2001b).
} 
operacionais 0 entendimento dessas dimensões presentes, concretamente no território;

- A análise das formas de atuação do homem sobre o meio físico-biótico deve levar em conta as crescentes injunções econômicas e políticas extra locais, ultrapassando as concepções inventariais de levantamento dos recursos e dos padrões de uso que marcam, ainda hoje, os procedimentos operacionais dos estudos ambientais;

- O conceito de 'pressão antrópica' deve ser reavaliado à luz de um complexo de interesses e decisões com base nas esferas políticas, econômicas, social e cultural presentes na sociedade ao longo do tempo. A concepção naturalizada do meio ambiente deve ser substituída pela leitura de um espaço geográfico interpretado como reflexo de processos naturais e como resultado de relações operadas no interior da sociedade.

\section{B. Procedimentos operacionais :}

- $\quad$ O ZEE Brasil deve ser executado através de quatro fases de trabalho: Planejamento do Projeto: Diagnóstico Ambiental; Prognóstico; e Implementação;

- A organização do Programa ZEE é feita através de consulta pública e envolvimento de segmentos sociais e respectiva abertura à participação deve ter caráter permanente;

- O diagnóstico ambiental não parte de levantamento aleatório e exaustivo de dados disponíveis, sendo orientado para objetivos previamente discutidos e fixados. Além disso, ele detém procedimentos específicos de correlação e síntese de informações que propiciam consulta e atualização na definição dos cenários;

- O objetivo principal do ZEE não necessita de mapeamentos sistemáticos de detalhamento, o que o inviabilizaria em termos econômicos e em tempo de execução;

- O prognóstico deverá elaborar, a partir da correlação das informações, a situação atual e os cenários de tendências, as unidades integradas propostas e as zonas de planejamento;

- A fase de planejamento é composta das seguintes atividades: articulação institucional; mobilização de recursos; identificação de demandas (principais agentes envolvidos e problemas ambientais e sócio-econômicos); análise e estruturação das informações; e consolidação do Projeto (detalhamento dos objetivos e orientação programática de acordo com as diretrizes gerais do Programa ZEE e áreas prioritárias de diagnóstico);

- A fase de diagnóstico deve contemplar uma integração sistematizada das análises setoriais. Os níveis diferenciados de integração são:

- Meio físico-biótico = deverá contemplar análise integrada do ambiente natural, para construir unidades naturais e detectar integridade dos sistemas naturais com suas potencialidades e limitações. A correlação de síntese interdisciplinar permite identificar arranjos espaciais pela convergência de semelhanças de seus componentes físicos e bióticos e de sua dinâmica constituindo os sistemas ambientais. São produtos de síntese: a) as unidades dos sistemas ambientais naturais (suas potencialidades e fragilidades); b) avaliação qualitativa da integridade dos sistemas naturais (equilíbrio ecológico), através da determinação de áreas para manutenção da biodiversidade existente dentro das unidades, permitindo que os processos ecológicos e seus serviços ambientais se mantenham;

- Dinâmica sócio-econômica = deverá contemplar a dinâmica da ocupação territorial e 0 uso dos recursos naturais, considerando a forma como a ação dos agentes sociais se manifesta no território. A unidade de pesquisa é o município. Os produtos de sínteses são: a) tendências de ocupação e articulação regional (ênfase na rede urbana e suas áreas de influência, bem como na infra-estrutura de circulação e comunicação); b) indicadores sociais agregados (espacialização 
de indicadores sociais básicos, com destaque para renda, saúde e educação da população);

- Diagnóstico da organização jurídico-institucional = deverá ser analisado através de três dimensões referentes: a) análise das malhas administrativas e ambientais que dividem o poder no território nacional; b) aos planos, programas e projetos que influenciam o uso atual e futuro do território; e c) à discussão das formas jurídicas e institucionais de implementação do Zoneamento;

- Situação atual = proporciona subsídios para analisar limitações e potencialidades naturais e socioeconômicas. Este diagnóstico apresenta níveis de conflitos e tipos de problemas segundo as unidades territoriais. Desse modo, são estabelecidos parâmetros para classificar a situação quanto ao desenvolvimento e meio ambiente do país segundo: a) efeitos das políticas públicas de desenvolvimento econômico e ocupação; b) presença de eixos induzidos ou estimulados por políticas públicas de desenvolvimento e de meio ambiente; c) efeitos antagônicos entre políticas públicas de desenvolvimento e meio ambiente; d) articulações entre políticas públicas de meio ambiente; e) efeitos de programas multilaterais, desenvolvidos com agências de cooperação técnicas e financeiras. A partir da análise da situação atual é necessário proposição de cenários com indicações de intervenções.

- Na fase de prognóstico são discutidas as possibilidades e condições do Zoneamento tornar norma legal e/ou programática. As principais atividades nesta fase são:

- Proposição das unidades de intervenção = as unidades de intervenção são áreas delimitadas em função da correlação dos produtos sintéticos gerados nas fases anteriores. As diferentes unidades de intervenção irão constituir um plano de informação do banco de dados;

- Cenários = visam apresentar as tendências de evolução de longo prazo. Para tal, 0 Zoneamento deverá quantificar e representar gráfica e em termos cartográficos os efeitos ambientais de simulações propostas sobre a situação atual, avaliando os impactos e medidas para seu incremento. Os cenários apresentam uma projeção no espaço de políticas sociais, ambientais e econômicas, devendo contemplar as fases de implementação das ações propostas com cronograma de ações de curto, médio e longo prazo com indicações para avaliação, acompanhamento e gestão das propostas sugeridas;

- Zonas e proposição de diretrizes gerais e específicas = as unidades de intervenção poderão ser repartidas em função de: a) órgãos que desempenham ações na região geográfica em que está inserida cada unidade; b) planos projetos e programas em desenvolvimento na área geográfica, em que está inserida cada unidade; c) aspirações do poder público federal, estadual, frentes de investimentos privados para o desenvolvimento; d) compatibilidade entre a intervenção requerida e os investimentos do PPA em programas na área social, infra-estrutura econômica, conservação dos recursos naturais, entre outros. Este processo dará origem as zonas ecológico-econômicas estabelecidas a partir do arranjo das unidades de intervenção. De modo geral, as diretrizes devem contribuir para: elevar 0 conhecimento técnico-científico da realidade, capacitar gestores públicos, ordenar e planejar a expansão dos setores agrícola e industrial, controlar e mitigar repercussões negativas da infra-estrutura viária, orientar aplicação de investimentos públicos, subsidiar implantação e gerenciamento de unidades de conservação, subsidiar decisões de projetos e programas de ampliação de infraestrutura; subsidiar soluções alternativas para aproveitamento dos recursos naturais e propor atividades produtivas que atendam às necessidades de melhoria das condições de vida da população e fortaleçam a economia regional. 
- A fase de subsídios à implementação do Zoneamento deve considerar os aspectos legais e programáticos da normatização, bem como sua integração aos planos de gestão;

- Em relação à Gestão, o Zoneamento não se limita a disciplinar o uso do território e indicar unidades restritivas de preservação, mas considera o processo de ocupação e de desenvolvimento, propondo alternativas e diretrizes programáticas;

- Em relação ao banco de dados do Zoneamento, este deverá apresentar as categorias (com os planos de informação correspondentes), os produtos de integração parciais (diagnósticos), a situação atual, as unidades de intervenção, os cenários, as zonas e, principalmente, possibilitar o processo de consultas espaciais e atualização dos dados e das informações existentes.

\subsubsection{Temáticas de interesse das regiões brasileiras para constarem no ZEE}

A partir dos workshops elaborados pelo MMA/SDS, foram traçadas as temáticas de interesse das regiões para o ZEE, listadas por VERÍSSIMO (2003, 39), conforme segue:

- Participação;

- Biodiversidade e serviços ambientais;

- Ocupação territorial e gestão dos recursos naturais;

- Zoneamento e políticas públicas;

- Organização urbano-regional no contexto do ZEE;

- Recursos hídricos;

- Desertificação;

- TURISMO $^{6}$;

- ZEE e estrutura produtiva;

- Estratégias de recuperação e uso sustentável da mata atlântica;

- Construção da sustentabilidade e o ZEE;

- Limites e possibilidades da valoração ambiental;

- Zoneamento como instrumento de planejamento do setor privado;

- Produção de energia e gerenciamento ambiental;

- Redes de informação e planejamento territorial;

- Grandes empreendimentos - implicações ambientais, sócio-econômicas e perspectivas sobre o ZEE.

Em relação ao turismo, esta atividade é mostrada como uma dessas demandas. No entanto, ela exerce forte relação com os demais temas de interesse. Essa constatação será explorada quando da construção do Modelo Referencial para o Turismo. 


\subsubsection{Problemas metodológicos do ZEE afetos ao turismo}

Os workshops regionais serviram para definir temáticas a serem consideradas pelo ZEE e para conhecer lacunas e os acertos que existem no Programa, bem como as expectativas futuras sobre viabilidade deste instrumento.

Em relação à questão metodológica, os técnicos dos estados mencionaram vários pontos que, segundo VERÍSSIMO (2003, 40 - 49), devem ser modificados e/ou acrescidos. As questões de interesse do Turismo listadas foram:

- Necessidade de integração com planos e programas de desenvolvimento nas esferas municipal, estadual e federal;

- Necessidade de flexibilização de escalas;

- Definição de indicadores; viabilização da participação das populações locais;

- Necessidade de articulação inter e intra-institucionais;

- E inclusão de indicadores relativos a valoração econômica dos recursos naturais.

\section{PANORAMA DO TURISMO NO BRASIL}

Para traçar um panorama do turismo no Brasil, torna-se necessário apresentar um histórico de suas políticas públicas, tendo como critério apenas as ações oficiais, fruto de leis, regulamentos, ações dos três poderes governamentais, suas instituições e agências reguladoras.

\subsection{Políticas públicas em turismo no Brasil}

A história das políticas públicas em turismo no Brasil é bastante recente. Até a instituição do Decreto Lei n.55, de 18 de novembro de 1966 -, que define a Política Nacional de Turismo (PNT), cria o Conselho Nacional de Turismo (CNTur) e a Empresa Brasileira de Turismo (EMBRATUR) ${ }^{7}$-, as políticas nacionais foram expressas em forma de diretrizes ou estratégias isoladas com

\footnotetext{
${ }^{7}$ Alterada em 1991 para Instituto Brasileiro de Turismo (Lei n. 8.181/91).
} 
objetivo de organizar e incentivar agências de turismo, transporte e hotelaria em detrimento de outros componentes do Sistema Turístico, induzindo formas de confinamento territorial da atividade e seu desenvolvimento parcial.

CRUZ (2002: 42-75) identifica, tendo por base a análise de todos os diplomas legais promulgados ao longo dos anos, inseridos em seus respectivos cenários de rupturas políticas, a história das políticas nacionais de turismo em três períodos, apresentados na figura abaixo. (Figura 2)

FIGURA 2 - RESUMO HISTÓRICO DAS POLÍTICAS NACIONAIS DE TURISMO (1938 - 2003)

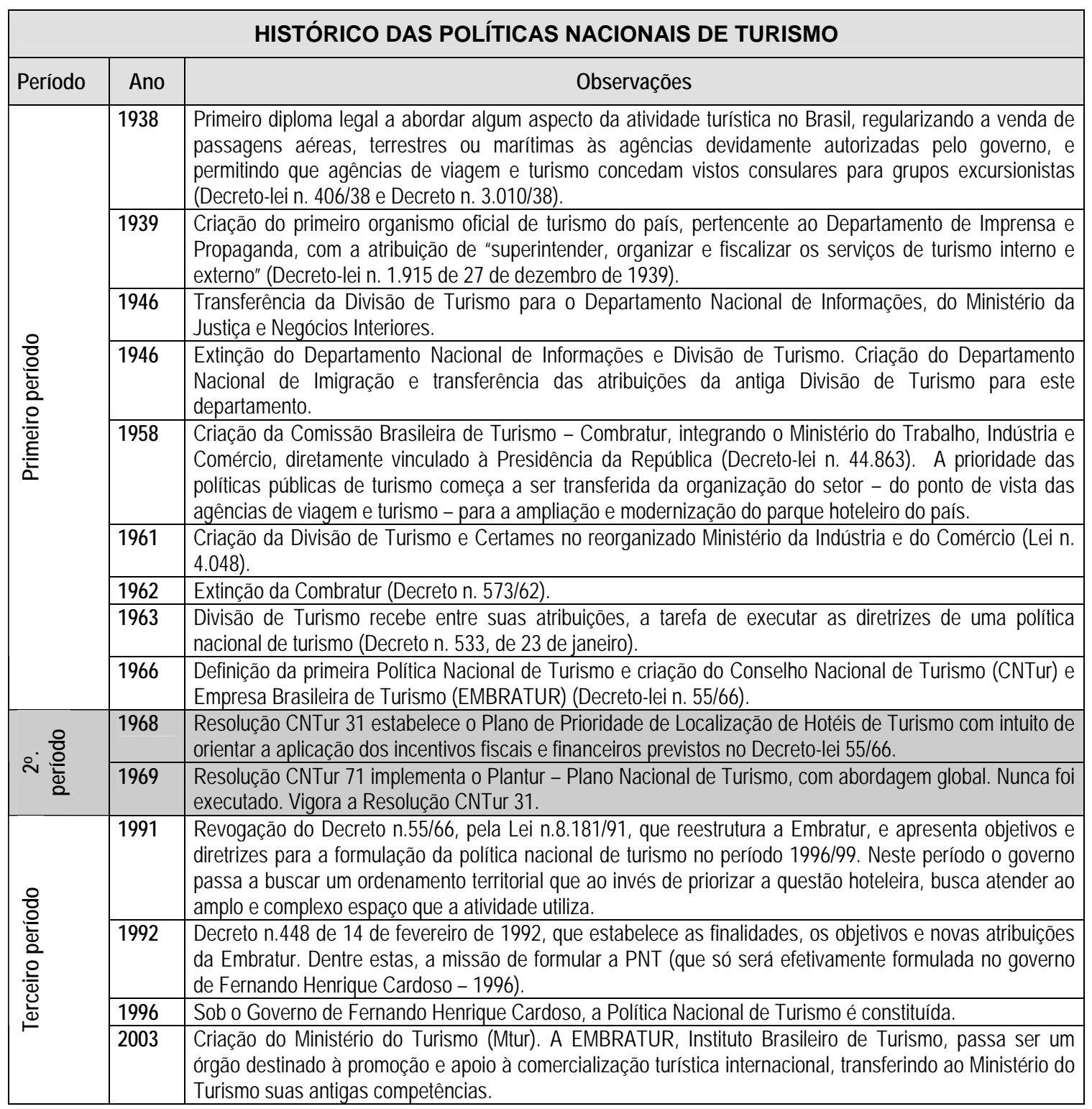


O primeiro período seria o de "pré-história" jurídico-institucional das políticas nacionais de turismo, iniciado com o Decreto Lei n.406 de 4 de maio de 1938, e rompido em 1966, pelo Decreto n. 55/66.

O Decreto Lei n.406/38 é o primeiro diploma legal a abordar algum aspecto da atividade turística no Brasil, estabelecendo normas para comercialização de passagens aéreas, terrestres ou marítimas.

Neste período foi criado o primeiro organismo oficial de turismo do país, ampliando o universo de atuação do Estado diante da atividade. A Divisão de Turismo, pertencente ao Departamento de Imprensa e Propaganda, diretamente vinculado a Presidência da República, nasce com a principal atribuição de "superintender, organizar e fiscalizar os serviços de turismo interno e externo" (Decreto-lei n.1.915 de 27 de dezembro de 1939). Isto confere a este setor um caráter de gestão e fiscalização, deixando de legislar sobre vendas de passagens ou funcionamento de agências apenas, para se ocupar também dos serviços relativos ao turismo interno e externo.

Neste período da história da Legislação do Turismo, há uma falta de compreensão sobre a competência política governamental em relação à questão turística. Seus assuntos e suas responsabilidades transitam em diferentes Departamentos, mudando a cada troca de governo, como um assunto do qual gestão alguma possuísse concordância e domínio.

Segundo CRUZ (2002:45):

\begin{abstract}
Esta circulação da atividade turística por tão diversas esferas da administração pública, conduz a diferentes interpretações. Uma delas esta associada ao fato de o turismo nunca ter estado entre as prioridades das políticas federais de desenvolvimento, do que seria resultado a 'fraqueza política' do setor, traduzida na inconstância dos organismos oficiais encarregados da gestão da atividade. (...) Tido como setor menos importante dentro do conjunto das atividades produtivas desenvolvidas no país, o turismo era possivelmente transferido de um para outro órgão da administração pública, devido à atuação de grupos ligados à atividade, e à sua respectiva articulação com as diversas esferas do poder público. Por fim, algumas dessas transferências teriam simplesmente decorrido de mudanças de governo, geralmente acompanhadas por reformas estruturais na máquina administrativa.
\end{abstract}

Entre estas transferências cita-se a extinção do Departamento de Imprensa e Propaganda, onde funcionava à época a Divisão de Turismo, pelo Decreto-lei 
n.7.528/45. Esta Divisão é transferida para o Departamento Nacional de Informações, do Ministério da Justiça e Negócios Interiores. Ainda no mesmo ano (1946), ambos, Departamento Nacional de Informações e Divisão de Turismo, são extintos com a queda do Estado Novo, cabendo ao Departamento Nacional de Imigração as atribuições da Divisão de Turismo (1946-58).

Em 1958, foi criada a Comissão Brasileira de Turismo - Combratur, integrando o Ministério do Trabalho, Indústria e Comércio, subordinada diretamente à Presidência da República (Decreto-lei n. 44.863) ${ }^{8}$.

Coube a Combratur coordenar, planejar e supervisionar a Política Nacional de Turismo, o que configura uma transferência das prioridades das políticas públicas, da organização do setor - do ponto de vista das agências de viagem e turismo -, para a ampliação e modernização do parque hoteleiro do país. Porém, a mesma acaba sendo extinta em 1962 (Decreto n. 573/62), antes mesmo de elaborar as diretrizes desta política.

Em 1961, em meio a um turbulento período político, é criada a Divisão de Turismo e Certames no reorganizado Ministério da Indústria e do Comércio (Lei n. 4.048), que vai receber entre suas atribuições (Decreto n. 533/63), "a tarefa de executar as diretrizes de uma política inexistente" (CRUZ, 2002:48).

A segunda fase tem início em 18 de novembro de 1966, com a promulgação do Decreto-lei n.55/66, que finalmente definiu e instituiu uma Política Nacional de Turismo, criando inclusive os organismos oficiais (CNTur e EMBRATUR) para levar a cabo sua efetivação.

Sob a Presidência de Castello Branco e integrando o Plano de Ação Econômica - PAEG (1964 -66), cria-se um sistema de incentivos fiscais e financeiros a partir do Decreto n.55/66, que reconhece o turismo como uma atividade atenuante das desigualdades sociais e econômicas do país (um dos objetivos do PAEG). Porém, segundo CRUZ (2002:49), o Decreto traz em seus artigos alguns equívocos que restringem a política a uma atividade decorrente de todas as iniciativas ligadas à indústria do turismo, que podem ser isoladas ou coordenadas entre si.

\footnotetext{
8 Considera-se um marco neste período (1958-62) o fato deste regimento (Decreto-lei n. 44.863/58) trazer reunidas tímidas diretrizes para uma política nacional de turismo.
} 
Uma política nacional de turismo pressupõe uma tomada de posição, por parte do poder público federal, ante a atividade, tendo como base o território nacional, capaz de estabelecer um norte, uma orientação tanto para o setor público como para o setor privado - incluindo-se setores de atividades que influem no desenvolvimento do turismo - no sentido de atingir os objetivos estabelecidos por essa política (sejam eles quais forem). Assim sendo, o Decreto-lei 55/66 equivoca-se ao considerar 'atividades isoladas' do setor público e/ou privado, como determinantes da política nacional de turismo. Tais atividades podem expressar, no limite, a existência de políticas locais e/ou regionais de turismo, não necessariamente consonantes com os objetivos estabelecidos por uma política nacional. (CRUZ, 2002, 49,50)

Através do Decreto n.55/66 é criado o Sistema Nacional de Turismo, constituído pelo CNTur $^{9}$, pela Embratur, ${ }^{10}$ e pelo Ministério das Relações Exteriores $^{11}$.

Segundo BECKER (1999:187):

O marco, nesta evolução da política, foi a criação da Embratur em 66, como uma autarquia, e que via o turismo como uma indústria nacional, importante, só que nos moldes do governo militar. A EMBRATUR (...) é uma autarquia em que a atividade era extremamente controlada, centralizada, quer dizer, exercendo um controle extremamente rígido da atividade turística, circundada pelas grandes companhias que não autorizavam o turismo, situada particularmente no Rio de Janeiro, onde estavam as grandes operadoras.

Em 10 de abril de 1968, a Resolução CNTur 31 estabelece o Plano de Prioridade de Localização de Hotéis de Turismo com intuito de orientar a aplicação dos incentivos fiscais e financeiros previstos no Decreto-lei n.55/66.

Ressalta-se que este Plano só teria validade ate a implementação do Plano Nacional de Turismo - Plantur - com uma abordagem global do turismo no país-, que foi definido e objetivado em 10 de abril de 1969, pela Resolução CNTur 71.

$\mathrm{Na}$ realidade, apesar de detalhados neste documento suas diretrizes, objetivos e metodologias para confecção, o Plantur nunca seria executado, vigorando o Plano de Prioridades de Localização de Hotéis de Turismo até 1992.

\footnotetext{
${ }^{9}$ Criado com a atribuição de "formular as diretrizes a serem obedecidas na política nacional de turismo" (Decreto-lei n. 60.224/67, art. $6^{\circ}$.) e extinto pela Lei n. 8.181/91.

${ }^{10}$ Existente atualmente com a função de promover e apoiar a comercialização turística internacional, mas, à época, foi a responsável por "estudar e propor ao CNTur os atos normativos necessários à promoção da política nacional de turismo e, bem assim, aqueles que digam respeito ao seu funcionamento" (Decreto -lei n. 60.224/67, art. $20^{\circ}$ ).

${ }^{11}$ Com a atribuição de divulgar o turismo nacional no exterior, "por meio de suas tarefas diplomáticas" (Decreto-lei n. $60.224 / 67$, art. 70 ).
} 
Entre 1966 e 1991, o Estado brasileiro promulgou diversos diplomas legais com o objetivo de regulamentar aspectos do desenvolvimento da atividade turística no país e, embora tais instrumentos, irregularmente distribuídos ao longo do tempo, não deixassem claros os objetivos das respectivas políticas nacionais de turismo que supostamente estariam subordinadas, isso não significa que tais políticas não tenham existido. $O$ que se pode concluir, a partir da análise deste conjunto de diplomas legais, é que as políticas nacionais de turismo, nesse período, falharam sob diversos aspectos, mas, principalmente, por reduzirem-se a aspectos parciais da atividade, em detrimento de uma abordagem estrutural e totalizante. (CRUZ, 2002: 42)

Com a revogação do Decreto n.55/66, pela Lei n.8.181, de 28 de março de 1991, que reestrutura a EMBRATUR, e apresenta objetivos e diretrizes para a formulação do que viria a ser a política nacional de turismo no período 1996/99, há o início do que CRUZ (2002: 56-67) considera o terceiro período da história das políticas nacionais de turismo do país.

Neste período o governo passa a buscar um ordenamento territorial que ao invés de priorizar a questão hoteleira, atenda ao amplo e complexo espaço que a atividade utiliza.

A Lei n.8.181/91 altera a EMBRATUR, antes configurada como empresa pública, para autarquia especial, concedendo mais autonomia à mesma e alterando sua denominação de Empresa Brasileira de Turismo para Instituto Brasileiro de Turismo. Entre suas novas finalidades, acrescenta o art $2^{\circ}$. da citada Lei: "formular, coordenar, executar e fazer executar a Política Nacional de Turismo - PNT".

O Brasil, neste período - governo Collor de Mello -, atravessa uma reforma da máquina administrativa bastante tumultuosa e agravada com o impeachment do então presidente. Neste contexto, surge o Decreto n. 448 de 14 de fevereiro de 1992, que estabelece as finalidades, os objetivos e novas atribuições da Embratur. Dentre estas, a missão de criar um Conselho para compor, com a Diretoria, a equipe que deveria formular a PNT (que só será efetivamente formulada no governo de Fernando Henrique Cardoso - 1996).

A principal mudança no significado do turismo em relação a toda política anterior - exposta acima -, segundo BECKER (1995:26), "estaria expressa na substituição da ênfase no desenvolvimento, para a valorização e preservação do patrimônio natural e cultural do país e para a valorização do homem". 
Em 1992, mesmo ano da reestruturação da EMBRATUR para formulação da Política Nacional de Turismo, o governo elabora o Plano Nacional de Turismo ${ }^{12}$ Plantur. No entanto, não havia Política implementada. O Plantur, portanto, por não constituir instrumento de efetivação de uma política (pois esta ainda não existia) não consegue sair do papel.

Em 1996, sob o Governo de Fernando Henrique Cardoso, a Política Nacional de Turismo é constituída como "o documento mais completo e detalhado da história das políticas federais para o turismo" (CRUZ, 2002:62).

Ao ler a Apresentação da Política Nacional de Turismo (1996-99), percebe-se a ênfase dada aos problemas de desigualdades regionais e geração de emprego e renda:

\begin{abstract}
Norteia esta Política o estabelecimento de uma nova equação para a promoção do desenvolvimento da economia brasileira em que, a exemplo do cenário internacional, o setor de serviços, cada vez mais, assumirá maior participação relativa na renda nacional. Ao mesmo tempo, por suas característica, o turismo contribuirá para promover a diminuição das desigualdades regionais; a geração de emprego e renda; a integração ao mercado de trabalho de um contingente populacional de baixa qualificação profissional, através da execução de atividades correlatas; o desenvolvimento sustentável de áreas com destacado patrimônio ambiental; e servirá de instrumento para a inserção competitiva do país no panorama global, através do estabelecimento de uma imagem externa positiva (PNT, 1996:6).
\end{abstract}

Esta política se fundamenta na descentralização no sentido do incentivo a atuação coordenada de agentes públicos e privados, estabelecendo parcerias efetivas para o "planejamento, controle, fiscalização e execução das ações" (PNT 1996-99). Também trata da questão da infra-estrutura básica e turística através da dotação de pólos turísticos brasileiros. Porém, o ordenamento territorial da atividade, efetivamente, é tratado de forma tímida.

Em 2003, foi criado o Ministério do Turismo (MTur), e a EMBRATUR passou a ser um órgão destinado à promoção e apoio à comercialização turística internacional, transferindo ao Ministério do Turismo suas antigas competências.

Em 30 de abril de 2003, o atual Ministro do Turismo, Walfrido dos Mares Guia, na ocasião de posse do Conselho Nacional de Turismo (CNTur), assumiu um compromisso expresso através do Plano Nacional do Turismo (2003-2007). Este

12 "com objetivo de constituir um instrumento de implementação da política nacional de turismo" 
documento, elaborado de forma coletiva, sob consulta de diversas regiões e setores representativos do turismo brasileiro, "procura traduzir uma concepção de desenvolvimento que, além do crescimento, busca a desconcentração de renda por meio da regionalização, interiorização e segmentação da atividade turística"13. Dentre os princípios orientadores para o desenvolvimento do turismo destacam-se os quatro vetores elementares do governo do Presidente Luís Inácio Lula da Silva:
a. Redução das desigualdades regionais e sociais
b. Geração e distribuição de renda
c. Geração de emprego e ocupação
d. Equilíbrio da balança de pagamentos

\section{MODELO REFERENCIAL DO TURISMO}

O turismo depende diretamente de planejamento, políticas e planos integrados e inseridos no Território. Logo, para subsidiar a elaboração do instrumento ZEE, a partir das demandas da atividade turística, é preciso conhecer se existe algum modelo referencial do turismo que deva ser contemplado pelo ZEE. Nesse caso, é apresentado, a seguir, um modelo referencial teórico do turismo ${ }^{14}$.

\subsection{Sistema de Turismo}

Há menos de duas décadas, o turismo no Brasil foi analisado sob o enfoque da Teoria Sistêmica pelo pesquisador Mário Carlos BENI ${ }^{15}$. Este trabalho é a principal referência brasileira para tratar da questão e é amplamente utilizado aqui.

Tendo em vista a complexidade da atividade turística e a busca de sistematizar essa atividade, o diagrama de contexto do SISTUR (figura 3) acaba determinando três grandes conjuntos em interação no sistema global. Cada conjunto

\footnotetext{
13 Mensagem do Senhor Ministro do Turismo. Plano Nacional do Turismo: Diretrizes, Metas e Programas. 2003-2007. Ministério do Turismo. Brasília. Abril de 2003. p.7.

14 Dentro do modelo referencial teórico proposto, consideram-se três grandes conjuntos: Relações Ambientais, Organização Estrutural e Ações Operacionais. Apesar de considerar que o ZEE exerce influencia sobre todos os conjuntos do sistema, e pela inviabilidade de analisar criteriosamente cada uma destas relações, foi dada ênfase ao Conjunto das Relações Ambientais e ao Conjunto da Organização Estrutural por motivos apresentados no ultimo parágrafo do presente capitulo. 15 BENI, Mário Carlos. Análise estrutural do turismo. 4.ed. rev. São Paulo: SENAC, 2001.
} 
terá vários componentes, que serão considerados, cada um deles, um sub sistema com funções próprias e características individualizadas, e estas são:

- O conjunto das Relações Ambientais;

- A Organização Estrutural;

- $\mathrm{E}$ as Ações Operacionais. 
FIGURA 3. SISTEMA DE TURISMO (SISTUR) - MODELO REFERENCIAL DO TURISMO CONJUNTO DAS RELAÇÕES AMBIENTAIS

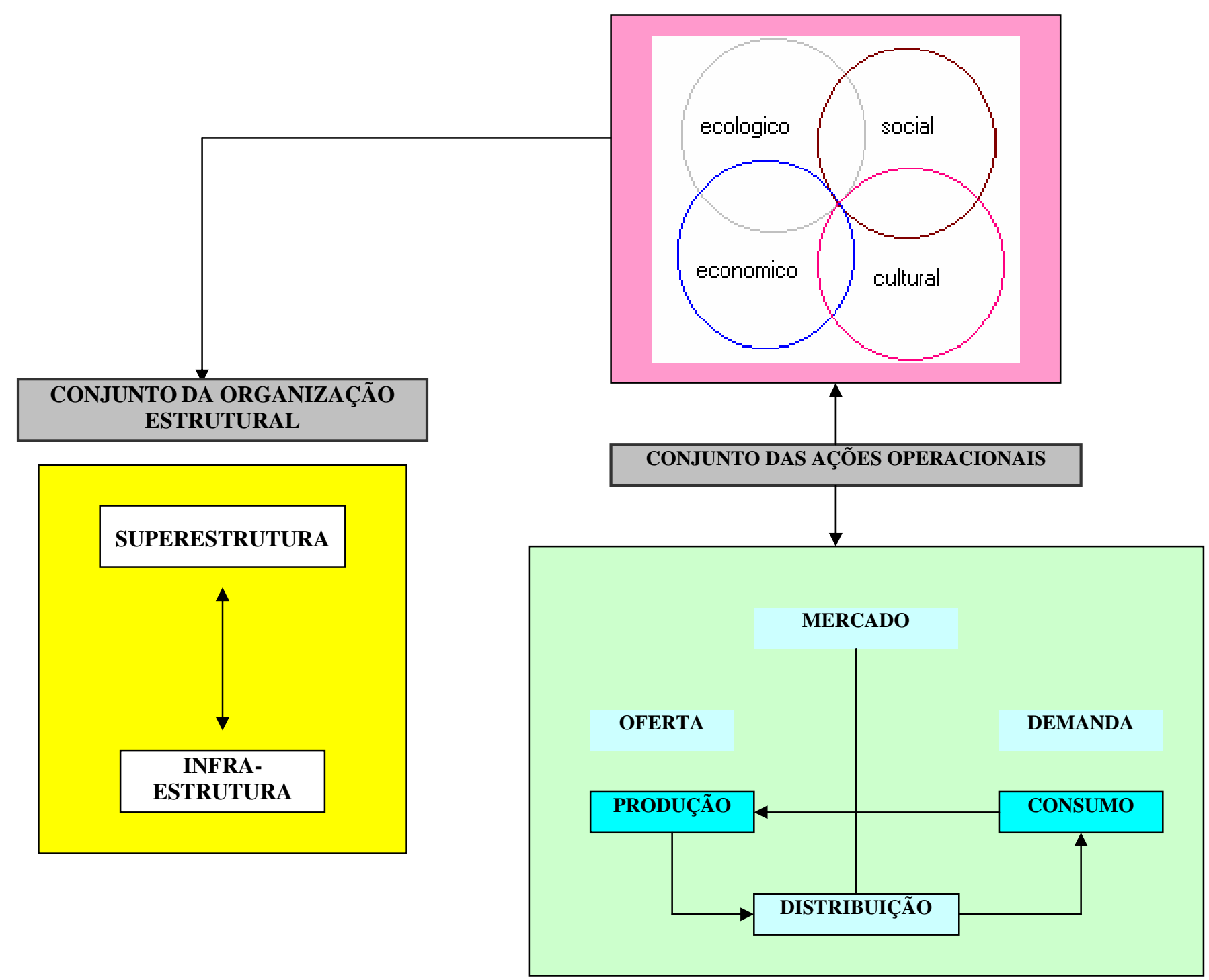

Fonte: Mario Carlos Beni, Sistema de turismo - construção de um modelo teórico referencial para aplicação na pesquisa em turismo, São Paulo, ECA/USP, 1988, tese doutorado. 
O Conjunto das Relações Ambientais possui quatro sub-sistemas (Figura 4):

$>$ Ecológico;

$>$ Social;

$>$ Cultural;

$>$ Econômico.

FIGURA 4 - CONJUNTO DAS RELAÇÕES AMBIENTAIS

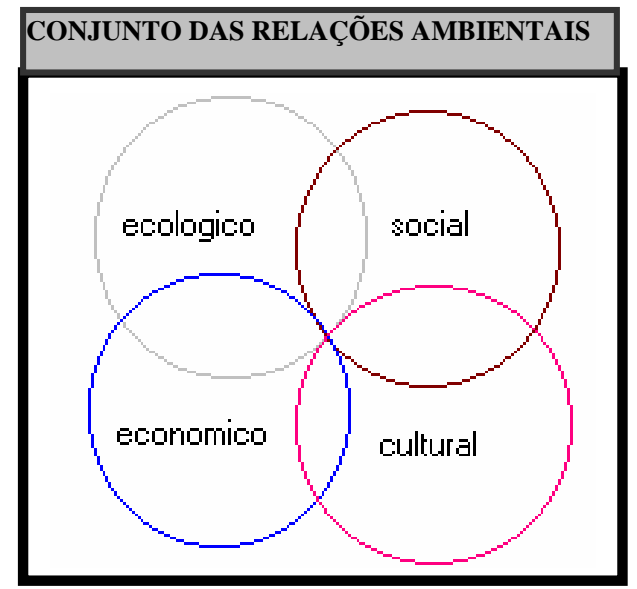

Fonte: Mario Carlos Beni, Sistema de turismo - construção de um modelo teórico referencial para aplicação na pesquisa em turismo, São Paulo, ECA/USP, 1988, tese doutorado.

O primeiro sub-sistema - Ecológico - trata da matéria-prima do turismo, e por isso abrange o espaço turístico natural e urbano, sua planificação, os atrativos turísticos e as conseqüências que o turismo pode causar para o meio natural. O segundo - Social - é referente à população autóctone, aos contatos sociais gerados pela atividade turística na localidade, ao perfil psico-sociológico do turista, e a estratificação social dos grupos de turistas. O terceiro sub-sistema - Cultural - trata da herança cultural da localidade (seu patrimônio cultural). E o quarto - Econômico - trata do ingresso de divisas na região, da receita acumulada, da geração de empregos, da formação do Produto Interno Bruto (PIB) e do efeito multiplicador da economia.

O Conjunto da Organização Estrutural é dividida em Superestrutura e Infraestrutura (Figura 5).

FIGURA 5 - CONJUNTO DA ORGANIZAÇÃO ESTRUTURAL

CONJUNTO DA ORGANIZAÇÃO ESTRUTURAL

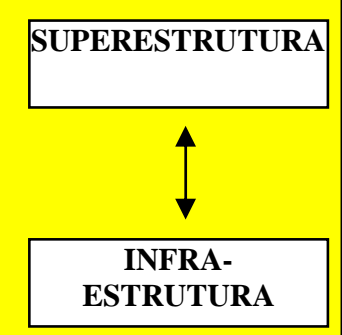


Segundo BENI (2001:99), a superestrutura refere-se à complexa rede organizacional pública e privada que permite harmonizar o sistema do turismo compreendendo a política oficial do turismo e sua ordenação jurídico-admistrativa "que se manifesta no conjunto de medidas de organização e de promoção dos órgãos e instituições oficiais, e estratégias governamentais que interferem no setor." (BENI, 2001:31) A infra-estrutura, do ponto de vista do autor, nada mais é que a análise das condições de acessibilidade à área de destinação turística e dos serviços.

O Conjunto das Ações Operacionais é o sub-sistema do Mercado, pois trata da oferta e demanda e do processo de produção, distribuição e consumo do produto turístico (Figura 6).

FIGURA 6- CONJUNTO DAS AÇÕES OPERACIONAIS

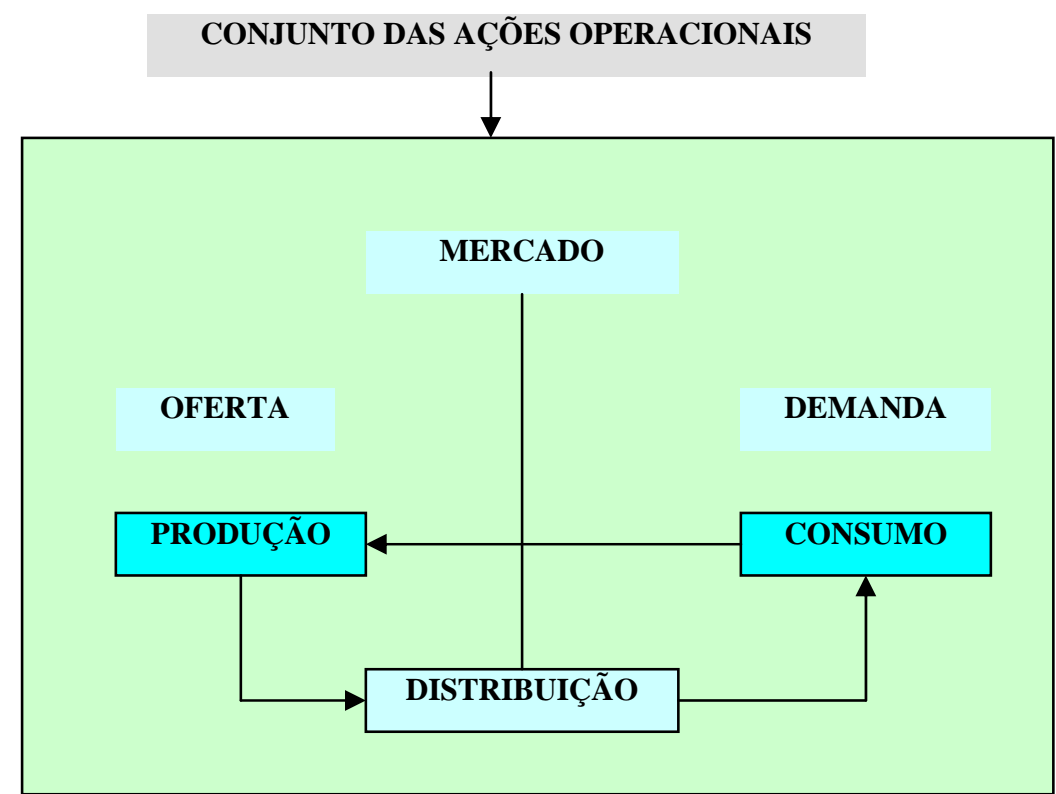

Fonte: Mario Carlos Beni, Sistema de turismo - construção de um modelo teórico referencial para aplicação na pesquisa em turismo, São Paulo, ECA/USP, 1988, tese doutorado.

Dos três grandes conjuntos apresentados acima, dois são contemplados na elaboração do Modelo de Referencial para o Turismo Sustentável: CONJUNTO DAS RELAÇÕES AMBIENTAIS e CONJUNTO DA ORGANIZAÇÃO ESTRUTURAL (ITEM INFRAESTRUTURA). A escolha foi para poder inserir o instrumento ZEE no contexto do planejamento turístico no Brasil; devido à constatação, quando da análise das políticas nacionais de turismo, da atenção dada pelo Mtur ao desenvolvimento da infra-estrutura básica, que compete prioritariamente a outras esferas do governo federal; e a fácil visualização da relação do Zoneamento Ecológico Econômico com a Infra-estrutura. 


\section{MODELO REFERENCIAL PARA TURISMO SUSTENTÁVEL DENTRO DO ZEE}

O Modelo Referencial para Turismo Sustentável dentro do ZEE foi construído a partir da Adaptação dos quadros "Sistematização dos resultados dos questionários do Workshop Dez anos do Programa ZEE" e "Temáticas para constar na metodologia de Zoneamento Ambiental" referentes à sistematização e temáticas de ZEE (VERISSIMO, 2003: 01-49); das premissas (VERISSIMO, 2003: 50 - 104); e adaptação do Modelo Referencial de turismo de BENI (2001).

\subsection{Marco referencial}

Os componentes que integram o marco referencial deste trabalho são:

\subsubsection{Desenvolvimento sustentável}

Há cerca de vinte anos surgiu uma proposta embrionária de mudança no desenvolvimento mundial e sua forma de apropriação dos recursos naturais. De fato, constatou-se uma crise decorrente, sobretudo, do esgotamento progressivo dos vários paradigmas de desenvolvimento experimentados desde o início do século. Ao mesmo tempo, ficou evidente que o progresso econômico não estava ligado às políticas concretas de proteção do meio ambiente e à administração sensata dos recursos naturais. Nesse caso, surgiu como saída, para parte desses problemas, o novo modelo de desenvolvimento mundial, denominado desenvolvimento sustentável.

O conceito de desenvolvimento sustentável não pretende só satisfazer as carências humanas básicas, mas ampliar a qualidade de vida das populações, mantendo a capacidade de suporte dos ecossistemas, garantindo assim o atendimento das futuras gerações. O desenvolvimento sustentável é o novo paradigma utilizado para propostas que visam o uso racional dos recursos naturais, sem comprometer a capacidade das gerações futuras atenderem às suas necessidades. E este modelo também é utilizado aqui para elaborar O MODELO REFERENCIAL DO TURISMO.

\subsubsection{Visão sistêmica}

Para efetivar o novo modelo de desenvolvimento é necessário reconhecer a complexidade dos sistemas naturais e humanos, e analisá-los sob diferentes perspectivas (física, biótica, social, cultural, econômica, política e legal). Esse tratamento sistêmico do Homem e Natureza fornece o contexto adequado para compatibilizar os objetivos de conservação e uso sustentável dos recursos naturais para o bem-estar humano (VERÍSSIMO, 2003). 
O sentido fundamental a considerar na palavra sistema, é o de síntese (palavra que tem exatamente a mesma origem), conjunto unificado, constituído de partes solidárias, de alguma forma articuladas entre si e não reunidas ao acaso. Por extensão, entende-se como sistema uma reunião criteriosa.

A teoria de sistemas foi desenvolvida na década de 1950 pelo biólogo austríaco Ludwig von Bertalanffy, como reação à metodologia de conceituação mecanicista que então prevalecia na ciência. Conforme CAPRA (1996: 46-55), para von Bertalanffy, o problema com a abordagem mecanicista é que a mesma negligenciava, ou mesmo negava ativamente aquilo que é essencial no fenômeno da vida (a interação). Como biólogo, se recusou a aceitar essa postura e desenvolveu a teoria de sistemas como um novo programa ou direção na filosofia da ciência contemporânea. Von Bertalanffy definiu sistema de forma simples, como um conjunto de elementos que interagem entre si, insistindo que essa definição contém tudo que é necessário, ou seja, oferece "um arcabouço conceitual geral para unificar várias disciplinas cientificas que se tornaram isoladas e fragmentadas." (CAPRA, 1996:55).

\footnotetext{
Mais tarde, outros autores apresentaram definições mais detalhadas sobre sistema. Basicamente ressaltam quatro pontos fundamentais, quais sejam:

1 - O conceito de interação entre os elementos do sistema, ou seja, a ação recíproca que modifica o comportamento ou a natureza desses elementos. Um elemento pode ser definido com o componente mínimo do sistema. Em si, um desses componentes pouco significa, só adquire significado em relação ao sistema que o compõe.

2 - O conceito que um sistema não é mera soma de elementos; é um todo, que não pode ser reduzido a suas partes. Esse todo possui qualidades que não existem, em isolamento, nas suas partes.

3 - O conceito central na teoria dos sistemas, enfatizado por von Bertalanffy, é o de organização. Organização pode ser definida com sendo o arranjo de relações entre elementos ou componentes, produzindo uma nova unidade, possuidora de propriedades não contidas nos componentes.

4 - Um sistema tende a ser um organismo com algum grau de complexidade. Esta complexidade pode ser maior ou menor, dependendo do número de elementos do sistema e do número e tipos de relações ligando, entre si, esses elementos. A complexidade depende, principalmente, das inter-relações existentes entre os elementos do sistema. Um sistema complexo se caracteriza por uma grande variedade de elementos, arranjados segundo níveis hierárquicos e interconectados por uma variedade de ligações estruturais e funcionais. (VERÍSSIMO, 2003: 53)
}

Abaixo, ainda segundo VERISSIMO (2003: 54-56) saõ apresentadas as caracterísitcas - chave do pensamento sistêmico: 


\section{CARACTERÍSTICAS-CHAVE DO PENSAMENTO SISTÊMICO}

MUDANCA DAS PARTES PARA O TODO - O primeiro critério, e o mais geral, é a mudança das partes para o todo. Os sistemas (sejam eles vivos ou sociais) são totalidades integradas cujas propriedades não podem ser reduzidas às partes menores. Suas propriedades essenciais, ou "sistêmicas", são propriedades do todo, que nenhuma das partes possui. Elas surgem das "relações de organização", das partes - isto é, de uma configuração de relações ordenadas que é característica dessa determinada classe de organismos ou sistemas. As propriedades sistêmicas são destruídas quando um sistema é dissecado em elementos isolados.

NÍVEIS SISTÊMICOS - O outro critério-chave do pensamento sistêmico é sua capacidade de deslocar a própria atenção, de um lado para o outro, entre níveis sistêmicos. Ou seja, sistemas dentro de outros sistemas. Por outro lado, diferentes níveis sistêmicos representam níveis de diferentes complexidades. Em cada nível, os fenômenos observados exibem propriedades que não existem em níveis inferiores. Em cada nível, as propriedades sistêmicas são denominadas de propriedades "emergentes", posto que emergem nesse nível em particular.

PENSAMENTO CONTEXTUAL- A diferença do pensamento mecanicista para 0 pensamento sistêmico diz respeito à relação entre as partes e o todo que foi invertida. $\mathrm{Na}$ ciência cartesiana havia a crença que, em qualquer sistema complexo, 0 comportamento do todo podia ser analisado em termos das propriedades de suas partes. A ciência sistêmica mostra que os sistemas vivos não podem ser compreendidos por meio de análise. A análise significa isolar alguma coisa a fim de entendê-la; na abordagem sistêmica, as propriedades das partes não são propriedades intrínsecas, mas podem ser entendidas apenas a partir da organização do todo. Em conseqüência disso, o pensamento sistêmico concentra-se não em blocos de construção básicos, mas em princípios de organização básicos. 0 pensamento sistêmico é "Contextual", o que significa colocar as propriedades no contexto de um todo mais amplo, em oposição ao pensamento analítico. Como explicar coisas considerando o seu contexto significa explicá-las considerando o seu meio ambiente, também podemos dizer que todo pensamento sistêmico é pensamento ambientalista (CAPRA, 1997).

MUDANCA DE OBJETOS PARA RELACÕES - REDE DE RELACÕES - Ao mesmo tempo, a física quântica mostrou que não há partes, em absoluto. Aquilo que denominamos parte é apenas um padrão numa teia inseparável de relações. Logo, a mudança das partes para 0 todo também pode ser vista como uma mudança de objetos para relações. $\mathrm{Na}$ visão mecanicista, o mundo é uma coleção de objetos. Estes interagem uns com os outros, e, portanto, há relações entre eles. Mas as relações são secundárias. Já na visão sistêmica, os próprios objetos são redes de relações, embutidas em redes maiores. Para o pensamento sistêmico as relações são fundamentais. As fronteiras dos padrões discerníveis ("objetos") são secundárias. Assim, passou-se a ter a percepção do mundo vivo como uma rede de relações.

O pensamento sistêmico em termos de metáfora é a rede de relações. Teia dinâmica de eventos inter-relacionados. Nenhuma das propriedades de qualquer parte dessa teia é fundamental; todas elas resultam das propriedades das outras partes, e a consistência global de suas inter-relações determina a estrutura de toda a teia. (CAPRA, 1996)

\subsubsection{Integridade ecológica e cultural}

Para efetivar o paradigma de desenvolvimento sustentável e introduzir a maneira sistêmica de pensar e planejar é preciso que os princípios da ecologia se 
manifestem também na educação, nas políticas públicas e dentro das comunidades (VERÍSSIMO, 2003: 55,56). Neste caso, é importante tratar do elo que une as comunidades ecológicas e humanas. Afinal, ambos são sistemas vivos, que exibem os mesmos princípios básicos de organização. Os princípios básicos da ecologia devem ser as diretrizes para construir comunidades humanas sustentáveis. A partir desses princípios básicos, deve-se procurar tratar essa rede de relações entre os ecossistemas naturais e humanos, dentro de uma proposta de desenvolvimento sustentável.

\begin{abstract}
"Uma forma de abordar esse elo entre os ecossistemas naturais e humanos é através da abordagem de 'Integridade Ecológica e Cultural'. A 'Integridade Ecológica' dos sistemas naturais e a 'Integridade Cultural' da sociedade são mantidas se esses sistemas permanecem em um estado de bem-estar" (KAY ${ }^{16}$, apud VERÍSSIMO, 2003, p. 56).
\end{abstract}

A Integridade Ecológica traduz dois aspectos fundamentais de sua organização: 1)Saúde = capacidade do sistema de alcançar e manter seu ponto operacional ótimo, mesmo quando submetido a perturbações ambientais e; 2) Autoregulação = capacidade do sistema de continuar sua evolução e desenvolvimento.

A Integridade Cultural reflete o uso sustentável dos recursos naturais, a qualidade de vida (saúde, bem-estar, valoração do capital natural e dos serviços ambientais); participação da sociedade nas questões relacionadas ao desenvolvimento sustentável; cooperação (sinergia) e valorização das diferenças culturais e da ética.

\title{
7.2. Premissas
}

Foram consideradas as seguintes premissas, a partir do marco referencial:

\subsubsection{Integrar políticas públicas}

É necessário integrar políticas públicas para que o desenvolvimento sustentável seja efetivado, dentro dos princípios sistêmicos, e considerando a necessidade de unir HOMEM E NATUREZA mantendo as integridades ecológica e cultural desses sistemas vivos.

${ }^{16} \mathrm{KAY}$, J.J. On the Nature of Ecological Integrity: some closing comments. In: WOODLEY, S.; KAY, J.; FRANCIS, G. (Ed.). Ecological Integrity and the Management of Ecosystems. USA: St. Lucy press, 1993. 
Nesse caso, é necessário integrar o planejamento e a política de turismo com o planejamento e as políticas econômicas, culturais, sociais, ambientais, urbanas e agrícolas.

\subsubsection{Utilizar unidades territoriais e ambientais}

É necessário utilizar, de forma simultânea, as unidades territoriais e ambientais do ZEE. Não existe a melhor unidade para trabalhar o ordenamento territorial e as questões ambientais. Cada uma tem sua especificidade e deve ser considerada tanto dentro do ZEE quanto pelo turismo quando se trabalha com questões afetas ao território e ao meio natural. Com o aparecimento do programa Sistema de Informações Geográficas (SIG), que trabalha com diversas informações espaciais simultaneamente, as quais estão todas relacionadas a um banco de dados, esta premissa fica ainda mais factível.

Em relação às unidades territoriais, é importante primeiro definir o que seja território. Ele é resultado da delimitação coletiva e de apropriação do espaço. Ou seja, conforme HEIDRICH ${ }^{17}$, citado por VERÍSSIMO (2003, p.82):

\footnotetext{
"A criação do TERRITÓRIO (com seus respectivos limites e fronteiras) consiste exatamente na maneira com a qual as civilizações se libertam desta condição de existência. No sentido exposto, a demarcação de TERRITóRIO objetiva impor domínios humanos sobre a existência em geral, tanto sobre as condições de extensividade como as de contigüidade e de vizinhança"
}

Já a organização funcional do território é a maneira pela qual a sociedade se apropria do espaço e a transforma em objeto, a partir de suas demandas e padronizações sociais. Conforme muda a sociedade mudam as formas de organização dos territórios e suas funções. (VERÍSSIMO, 2003)

Pelo exposto, as unidades territoriais do ZEE a serem consideradas são: estados, municípios, unidades de conservação e áreas protegidas.

As unidades ambientais são fragmentos do espaço geográfico, compostas de um conjunto de elementos que caracterizam um determinado sistema natural. No caso específico do ZEE, as unidades ambientais mais utilizadas são: BACIAS HIDROGRÁFICAS, GEOSSISTEMAS, ECORREGIOES, SISTEMAS DE TERRA E UNIDADES DA PAISAGEM (VERÍSSIMO, 2003: 85 - 87).

\footnotetext{
17 HEIDRICH, A . L. Organização do espaço: uma revisão conceitual em face dos processos de reestruturação econômica e de reforma do Estado. In: Revista Redes. Desenvolvimento regional. Revista de mestrado. V.1,n.2. Santa Cruz do Sul: Editora da UNISC,dez.1996.
} 


\subsubsection{Tratamento integrado das questões urbanas, rurais e de manutenção dos sistemas naturais.}

Para que haja integração de políticas públicas e utilização simultânea das unidades territoriais e ambientais é necessário tratamento integrado das questões urbanas, rurais e de manutenção dos sistemas naturais. Isto significa que a cidade, as áreas rurais e as unidades de conservação e áreas protegidas devem ser vistas de forma integrada.

Para o turismo isso fica bem claro, como o caso recente da hantavirose no Distrito Federal. As cidades estão se expandindo sem critérios e sem saneamento básico, para dentro de uma área rural. Esta, por sua vez, está na borda ou é área de corredor dos ratos silvestres que habitam o Cerrado. Os ratos, por sua vez, estão perdendo sua alimentação, porque seu habitat foi destruído. Como eles se proliferam rapidamente, e seus predadores foram exterminados, eles necessitam buscar um alimento que já não se encontra com facilidade dentro do Cerrado, logo, vão em direção às áreas urbanas. Como alguns são hospedeiros do vírus da hantavirose, ao defecarem, ou urinarem ou deixarem sua saliva nas áreas rurais e urbanas, acabam por contaminar a população urbana e rural. Como conseqüência para o turismo, registra-se uma queda nessas últimas semanas, no turismo rural, de cerca de $50 \%$ do movimento de turistas. ${ }^{18}$. Alguns empresários do setor dizem que se 0 surto continuar, haverá demissões e falências no setor.

\subsection{O turismo dentro das temáticas e metodologia do programa ZEE}

\subsubsection{O turismo dentro das temáticas prioritárias do programa ZEE: modelo 1}

O workshop dos "Dez anos do Programa ZEE”, segundo VERÍSSIMO (2003) serviu para conhecer as lacunas e os acertos que o Programa tem, bem como as expectativas futuras. Parte destas respostas foram obtidas a partir dos questionários distribuídos às equipes estaduais de ZEE e aos participantes do encontro. Em relação à questão temática e metodológica, foram mencionados vários pontos que devem ser modificados e/ou acrescidos. Esse material foi estruturado e

${ }_{18}$ Correio Braziliense. Saúde. 31 de julho de 2003. 
sistematizado por temas de interesse prioritários para o Programa ZEE ${ }^{19}$. Tendo esse material como base, segue abaixo sua adaptação a partir das demandas do turismo (Figura 7).

19 “ Sistematização dos resultados dos questionários do Workshop "Dez anos do Programa ZEE” , Veríssimo, M. op. cit. 
FIGURA 7 - TEMÁTICAS CORRELATAS AO TURISMO A SEREM CONTEMPLADAS PELA METODOLOGIA DE ZONEAMENTO - 2004

\begin{tabular}{|c|c|c|}
\hline Ponto-chave & Questão Prioritária & Considerações relativas ao planejamento territorial do turismo \\
\hline \multirow{4}{*}{$\begin{array}{l}\text { Questões } \\
\text { Gerais } \\
\text { Metodológicas }\end{array}$} & Definir qual a melhor unidade ambiental para o ZEE; & Todas as unidades ambientais apresentam relação com o ordenamento da atividade turística. \\
\hline & Homogeneizar a linguagem do ZEE para as equipes; & $\begin{array}{l}\text { Esta questão facilitará a utilização das mesmas pelos profissionais do turismo e a interface de opiniões entre estes e os } \\
\text { demais profissionais envolvidos. }\end{array}$ \\
\hline & Gerar produtos mais fáceis de serem disponibilizados e divulgados; & $\begin{array}{l}\text { Com esta questão, os produtos poderão ser utilizados pelos planejadores e gestores do turismo, inclusive como instrumento } \\
\text { de planejamento do setor privado. }\end{array}$ \\
\hline & Considerar as escalas municipais dentro do ZEE; & $\begin{array}{l}\text { Todas as escalas territoriais são fundamentais, conforme apresentado nas premissas. Mas através de escalas municipais será } \\
\text { possível cruzar informações coletadas através de outros instrumentos de planejamento, como é o caso do Inventario da Oferta } \\
\text { Turística, além de auxiliar na elaboração e monitoria de Planos Diretores. }\end{array}$ \\
\hline \multirow{7}{*}{$\begin{array}{l}\text { Planejamento } \\
\text { e Gestão } \\
\text { Territorial e } \\
\text { dos Recursos } \\
\text { Naturais }\end{array}$} & Necessidade de inserção dos espaços urbanos no ZEE; & Viabilizará o planejamento, elaboração e gestão de Planos Diretores inserindo análises especificas na área turística municipal. \\
\hline & Necessidade de inclusão das unidades de conservação no ZEE; & $\begin{array}{l}\text { Oferecerá dados para Planos de Manejo, além de auxiliar no planejamento do uso espaço turístico, apontando seus acessos, } \\
\text { atrativos, pontos de apoio ao turismo, etc. }\end{array}$ \\
\hline & $\begin{array}{l}\text { Necessidade de inclusão das zonas de amortecimento e } \\
\text { corredores ecológicos no ZEE; }\end{array}$ & $\begin{array}{l}\text { O aproveitamento turístico destas áreas se dá com muita frequiência tendo em vista sua localização privilegiada, próxima a } \\
\text { centros urbanos, e com a atual legislação ambiental que incentiva a criação de Reservas Privadas do Patrimônio Natural } \\
\text { (RPPN). Estas Reservas estão auxiliando a composição de corredores e mosaicos ecológicos auxiliando a preservação do } \\
\text { meio ambiente. Muitas das RPPN's, existentes no país, exploram o turismo (ecoturismo) e incentivam pesquisas. A inclusão } \\
\text { destas zonas no ZEE auxiliará na definição de cenários e zonas de Interesse para o Turismo. É importante citar que este } \\
\text { assunto já esta sendo discutido em parceira do MMA e do Mtur, que deve resultar na elaboração da "Agenda ambiental para o } \\
\text { turismo". Outra questão é a hantavirose, que mostra essa necessidade de zonas de amortecimentos para evitar problemas } \\
\text { que reflitam de forma negativa para atividades de turismo. }\end{array}$ \\
\hline & $\begin{array}{l}\text { Necessidade de criação de indicadores de sustentabilidade } \\
\text { agrícola dentro do ZEE; }\end{array}$ & Contempla-se aqui a relação das políticas de incentivo para o turismo rural e agroturismo. \\
\hline & $\begin{array}{l}\text { Considerar as diversidades culturais locais e regionais quando da } \\
\text { formulação dos indicadores de ZEE; }\end{array}$ & Fundamental para a sustentabilidade do turismo no que concerne a sociologia do turismo. \\
\hline & Construir cenários para o território; & São estes cenários que deverão indicar Áreas Especiais de Interesse Turístico ${ }^{20}$. \\
\hline & Incluir a questão dos recursos hídricos no ZEE. & $\begin{array}{l}\text { Prever e garantir a sustentabilidade da atividade através do uso dos recursos hídricos provocados pelo aumento da demanda } \\
\text { sazonal em áreas de interesse turístico. Como mencionado, as bacias hidrográficas, dentre as unidades ambientais, é a mais } \\
\text { utilizada pela atividade turística. }\end{array}$ \\
\hline \multirow{3}{*}{ Participação } & $\begin{array}{l}\text { A participação deve significar capacitação das equipes de ZEE } \\
\text { para trabalhar o instrumento; }\end{array}$ & $\begin{array}{l}\text { Devem compor as equipes profissionais da área de turismo e estes devem estar capacitados para trabalhar o instrumento } \\
\text { defendendo a demanda do turismo e integrando-as às demais atividades dos outros setores. }\end{array}$ \\
\hline & Divulgação dos resultados do ZEE; & $\begin{array}{l}\text { A ampla divulgação dos resultados, em linguagem adaptada aos profissionais do setor turístico, deverá auxiliar e dar a base } \\
\text { para o planejamento e aproveitamento turístico da área a ser zoneada. }\end{array}$ \\
\hline & $\begin{array}{l}\text { Atuação das comunidades na formulação do ZEE e nas demais } \\
\text { etapas. }\end{array}$ & $\begin{array}{l}\text { Bem como preconizam os atuais programas de turismo, a participação da comunidade provoca a descentralização das ações } \\
\text { e garante o envolvimento e a sustentabilidade do processo de planejamento. }\end{array}$ \\
\hline \multirow[t]{2}{*}{$\begin{array}{l}\text { Políticas } \\
\text { Públicas }\end{array}$} & $\begin{array}{l}\text { Procurar integrar na metodologia as políticas urbanas, agrícolas, } \\
\text { ambientais (recursos hídricos, florestal, planos de manejo das } \\
\text { unidades de conservação, minerais etc), fundiárias, econômicas, } \\
\text { entre outras afetas ao ordenamento territorial, com vista a se } \\
\text { conhecer os conflitos sócio-ambientais; }\end{array}$ & $\begin{array}{l}\text { Com a garantia desta integração, o turismo se beneficia, pois depende destas políticas para auferir bons resultados. Isso é } \\
\text { considerado dentro das premissas deste trabalho. }\end{array}$ \\
\hline & $\begin{array}{l}\text { Definir conflitos sócio-ambientais e legais e procurar especializá- } \\
\text { los; }\end{array}$ & $\begin{array}{l}\text { Com uma previsão e espacialização destes conflitos podem-se definir estratégias em conjunto com outros órgãos públicos } \\
\text { (nacional, regional, estadual e municipal) para a criação de programas direcionados a estas regiões utilizando o turismo como } \\
\text { (re)ordenador de território e fator para amenizar conflitos. }\end{array}$ \\
\hline
\end{tabular}

${ }^{20}$ Conforme disposto na Lei no. 6.513, de 20 de dezembro de 1977. 


\subsubsection{O turismo dentro das temáticas prioritárias do programa ZEE: modelo 2}

Outro resultado, fruto do workshop nacional e cinco workshops regionais, foi a proposta de uma estrutura geral do Programa ZEE com indicativo de diretrizes metodológicas básicas para a elaboração do ZEE no território nacional. O documento intitulado "Diretrizes metodológicas para o Zoneamento Ecológico-Econômico", entregue na ocasião do "Encontro para consolidação da metodologia do ZEE para o Brasil", apresenta a concepção geral, os arranjos institucionais, os fundamentos conceituais e as diretrizes para os procedimentos operacionais necessários à execução do ZEE. Em relação à questão metodológica, foram definidas diretrizes para o Projeto ZEE Brasil e Projetos regionais e estaduais de Zoneamento.

Esse material foi estruturado e sistematizado por temas de interesse prioritários para o Programa ZEE. ${ }^{21}$. A seguir, é feita outra adaptação a partir das demandas do turismo (Figura 8).

21 "Temáticas para constar na metodologia de Zoneamento Ambiental", Veríssimo, M. op. cit. 



\begin{tabular}{|c|c|c|}
\hline TEMÁTICAS & $\begin{array}{l}\text { WORKSHOP NACIONAL e } \\
\text { WORKSHOPS REGIONAIS }\end{array}$ & $\begin{array}{l}\text { INDICATIVO DE DIRETRIZES METODOLÓGICAS PARA PLANEJAMENTO TERRITORIAL DO } \\
\text { TURISMO } \\
\text { Inserção do Turismo no ZEE }\end{array}$ \\
\hline $\begin{array}{l}\text { Questões } \\
\text { gerais }\end{array}$ & $\begin{array}{l}\text { 1. REFERENCIAL } \\
\text { METODOLÓGICO = } \begin{array}{c}\text { TEÓRICO- } \\
\text { princípios }\end{array} \\
\text { sistêmicos para tratamento de dados; } \\
\text { 2. UNIDADE AMBIENTAL = definir melhor } \\
\text { a unidade ambiental; } \\
\text { 3. ESCALA = (A) inclusão das escalas } \\
\text { municipal, estadual e federal; (B) } \\
\text { flexibilização de escalas; } \\
\text { 4. INDICADORES = integração dos } \\
\text { indicadores nas diferentes escalas de } \\
\text { trabalho; } \\
\text { 5. EQUIPES = homogeneizar conceitos e } \\
\text { procedimentos; } \\
\text { 6. PRODUTOS = disponibilidade e } \\
\text { divulgações fáceis. }\end{array}$ & $\begin{array}{l}\text { 1. Tendo em vista que no documento não esta clara a adoção da visão sistêmica em termos operacionais, é } \\
\text { importante salientar que tanto no que concerne à estratégia tática como no aspecto teórico-metodológico, o } \\
\text { sistema do turismo deve estar inserido entre os temas abordados, pois exerce forte influência no uso do } \\
\text { território, do ponto de vista da organização ambiental22. } \\
\text { 2. Todos os indicadores para definir as unidades ambientais deverão contribuir para determinar áreas de } \\
\text { interesse Turístico, principalmente no que diz respeito a qualquer tipo de turismo que utilize a natureza como } \\
\text { pano de fundo (matriz). E na identificação das potencialidades e limitações dos sistemas naturais que o } \\
\text { planejador do turismo deverá considerar estratégias e políticas para integrá-las a outras políticas públicas, } \\
\text { como preconiza a "agenda ambiental do turismo" que esta sendo elaborada pelo MMA e Mtur. } \\
\text { 3. (A) Considerando que o turismo depende do município para se desenvolver, as informações } \\
\text { socioeconômicas deverão apresentar recortes tanto estaduais quanto municipais, conforme apontado nas } \\
\text { premissas deste trabalho. } \\
\text { (B) É importante que as escalas e dimensões sejam complementares e apresentem o mesmo enfoque e } \\
\text { linguagem. Os planejadores do turismo definem sua demanda utilizando terminologias e procedimentos } \\
\text { operacionais específicos, que devem ser criados em articulação com as demais instituições, visto que ele } \\
\text { utilizará delas com freqüência. } \\
\text { 4. Esta integração fornecerá dados urbanos e ambientais que irão auxiliar a criação de indicadores para o } \\
\text { turismo, auxiliando na definição de áreas de interesse para o turismo²3. } \\
\text { 5. É necessário ter uma arena de debates entre as equipes do ZEE para encontrar afinidades e campos } \\
\text { comuns de atuação e demonstrar divergências em relação ao objeto estudado. Nestas equipes, a presença } \\
\text { de profissionais do turismo capacitados para a elaboração de métodos, e para integrar as diferentes } \\
\text { informações é fundamental. }\end{array}$ \\
\hline
\end{tabular}

${ }^{22}$ Conforme apresentado no Modelo Referencial de Mario Carlos Beni.

23 Vide Lei No. 6.513, de 20 de dezembro de 1977. 


\begin{tabular}{|c|c|c|}
\hline TEMÁTICAS & $\begin{array}{l}\text { WORKSHOP NACIONALI } \\
\text { WORKSHOPS REGIONAIS }\end{array}$ & INDICATIVO DE DIRETRIZES METODOLÓGICAS - MMA/SDS \\
\hline \multirow{5}{*}{$\begin{array}{c}\text { Planejamento } \\
\text { e } \\
\text { Gestão } \\
\text { Territorial e dos } \\
\text { Recursos Naturais }\end{array}$} & $\begin{array}{l}\text { 1. ESPAÇOS = inserção dos espaços } \\
\text { urbanos. }\end{array}$ & $\begin{array}{l}\text { 1. Tendo em vista que a rede de cidades, e sua articulação com a região de entorno } \\
\text { constituem um fator fundamental na definição das unidades territoriais e, considerando que } \\
\text { elas são responsáveis por considerável parte do turismo, conclui-se que esta inserção, além } \\
\text { de contribuir para a elaboração de Plano Diretor, contribuirá para o planejamento do turismo. }\end{array}$ \\
\hline & $\begin{array}{l}\text { 2. TERRITÓRIO =(A) inclusão unidades de } \\
\text { conservação; }(B) \text { áreas prioritárias para } \\
\text { criação de unidades de conservação. }\end{array}$ & $\begin{array}{l}\text { 2. (A) As unidades de conservação devem vir acrescidas da viabilidade para uso turístico, } 0 \\
\text { que deve ser determinado de acordo com análises jurídico-institucionais realizadas em } \\
\text { parceria com profissionais de turismo pelas equipes ZEE. (B) A definição de áreas } \\
\text { prioritárias auxiliará no planejamento do turismo em áreas naturais. }\end{array}$ \\
\hline & $\begin{array}{l}\text { 3. UNIDADE AMBIENTAL = incluir bacia } \\
\text { hidrográfica. }\end{array}$ & $\begin{array}{l}\text { 3. A Bacia Hidrográfica, como recorte do Zoneamento oferece ao planejador turístico a } \\
\text { possibilidade de prever a capacidade real e potencial de turistas em determinada localidade } \\
\text { sem causar danos ao abastecimento local. }\end{array}$ \\
\hline & $\begin{array}{l}\text { 4. INDICADORES= considerar diversidades } \\
\text { culturais locais e regionais; }\end{array}$ & $\begin{array}{l}\text { 4. Considerando a diversidade cultural, o ZEE trata uma das questões do Conjunto das } \\
\text { Relações Ambientais que compõe o turismo (vide cap. 6). }\end{array}$ \\
\hline & 5. PRODUTOS = construir cenários. & $\begin{array}{l}\text { 5. A construção de cenários auxilia a determinação do que se pretende para cada região. } \\
\text { Os planejadores do turismo podem se utilizar os cenários para planejar a atividade. }\end{array}$ \\
\hline
\end{tabular}




\begin{tabular}{|c|c|c|}
\hline TEMÁTICAS & $\begin{array}{l}\text { WORKSHOP NACIONALI } \\
\text { WORKSHOPS REGIONAIS }\end{array}$ & INDICATIVO DE DIRETRIZES METODOLÓGICAS - MMA/SDS \\
\hline \multirow{3}{*}{ Participação } & $\begin{array}{l}\text { 1. REFERENCIAL TEÓRICO-METODOLÓGICO = } \\
\text { atuação das comunidades nas etapas do } \\
\text { Zoneamento; }\end{array}$ & $\begin{array}{l}\text { 1.O processo de envolvimento e participação garante a sustentabilidade das definições e prioridades do ZEE, além de } \\
\text { possibilitar a maior representatividade dos interesses da comunidade do local zoneado. O que também auxilia no } \\
\text { planejamento das vocações turísticas que venham a ser definidas para a localidade, assegurando a descentralização, } \\
\text { como incentiva a atual política de turismo no Brasil. }\end{array}$ \\
\hline & $\begin{array}{l}\text { 2. EQUIPES = (A) capacitação das equipes; (B) } \\
\text { equipes inter e intra-institucionais; }\end{array}$ & $\begin{array}{l}\text { 2. Capacitação = (A) Deverão ser realizados cursos específicos, seminários, workshops, palestras, treinamento em } \\
\text { serviço etc, buscando a capacitação dos envolvidos, incluindo-se entre estes os profissionais de turismo. (B) } \\
\text { Participação democrática }=\text { Parcerias também devem ser incentivadas entre diversos níveis da administração pública } \\
\text { (federal, estadual e municipal) e entre estes e organizações do terceiro setor e instituições privadas, onde a } \\
\text { participação dos representantes do segmento do turismo devE estar incluída. }\end{array}$ \\
\hline & $\begin{array}{l}\text { 3. PRODUTOS = divulgação dos produtos para as } \\
\text { comunidades. }\end{array}$ & $\begin{array}{l}\text { 3. A ampla divulgação dos resultados à comunidade irá garantir o envolviemto e participação dos mesmos. } \\
\text { O planejamento do uso do espaço não pode ser estritamente técnico, devendo considerar os objetivos, os valores e } 0 \\
\text { consenso entre os diferentes atores sociais envolvidos, como preconizam os princípios da participação. Por isso é } \\
\text { desejável que haja um intenso processo de mobilização da comunidade em todas as fases. A descentralização } \\
\text { também se sobressai neste contexto, tanto na execução quanto no monitoramento das atividades, o que possibilita } \\
\text { "uma melhor moldagem dos serviços às realidades socioeconômicas e culturais de cada localidade, em contraste com } \\
\text { a "excessiva" padronização e rigidez dos distantes governos centrais" (Tendler, 1997)24. }\end{array}$ \\
\hline \multirow{2}{*}{$\begin{array}{l}\text { Políticas } \\
\text { Públicas }\end{array}$} & $\begin{array}{l}\text { 4. REFERENCIAL TEÓRICO-METODOLÓGICO = } \\
\text { integrar políticas públicas com vista a conhecer } \\
\text { conflitos; }\end{array}$ & $\begin{array}{l}\text { 4. A integração das políticas sobre o território servirá para evitar conflitos legais, o que trará benefícios ao turismo visto } \\
\text { que ele se processa sobre o mesmo território. }\end{array}$ \\
\hline & $\begin{array}{l}\text { 5. INDICADORES = (A) definir conflitos sócio- } \\
\text { ambientais e legais e procurar espacializá-los; } \\
\text { (B) incluir eixos econômicos de integração e } \\
\text { desenvolvimento nacionais. }\end{array}$ & $\begin{array}{l}\text { (A) Com a utilização do SIG é possível espacializar estes conflitos, auxiliando o planejamento do turismo. } \\
\text { (B) Dentro desta inclusão, seria interessante que os programas do Ministério de Turismo que determinam eixos } \\
\text { de desenvolvimento da atividade fossem também contemplados. }\end{array}$ \\
\hline
\end{tabular}

${ }^{24}$ Apud CAMPANHOLA, C. A Reestruturação Do Meio Rural: Implicações para o Zoneamento Ecológico-Econômico Brasileiro. . In: Programa Zoneamento Ecológico-Econômico: Diretrizes Metodológicas para o Zoneamento Ecológico-Econômico do Brasil. Brasília: MMA/SDS, 2001. 


\subsection{Modelo referencial do turismo como base para elaborar modelo referencial para turismo sustentável dentro do ZEE}

Dos três grandes conjuntos apresentados, referentes ao modelo referencial do turismo, dois são utilizados para elaborar o Modelo de Referencial para o Turismo Sustentável: Conjunto da Organização Estrutural (Item Infraestrutura) e Conjunto das Relações Ambientais. A escolha foi para poder inserir o planejamento turístico no Brasil dentro do contexto do instrumento ZEE.

A seguir, a adaptação feita em relação aos dois itens do modelo.

\subsubsection{Infra-estrutura para o turismo dentro do ZEE}

Segundo CRUZ (2002: 33-74), o turismo no Brasil é uma atividade essencialmente urbana. Se os atrativos turísticos não estão alocados nas concentrações urbanas, todos os outros recursos dos quais o turismo necessita estão (alimentação, hospedagem, comunicação, bancos, etc). Porém, este fato não justifica as políticas de turismo estarem cumprindo a função das políticas urbanas. O cerne deste problema reside na falta de concatenação das políticas de turismo, urbanas e demais políticas afetas ao uso e ocupação do território. Tem prevalecido uma visão estreita, confusa e setorial do que seja infra-estrutura dentro do ordenamento territorial. Um melhor desempenho do turismo no país depende das políticas urbanas, com destaque para a infra-estrutura urbana.

Tendo por base a Estrutura Referencial de turismo apresentada por BENI (2001) e a Análise Macroeconômica do estado do Rio Grande do Sul ${ }^{25}$, foi criado um quadro com os principais aspectos a serem considerados no âmbito de infra-estrutura básica dentro do ZEE (Figura 9):

${ }^{25}$ Realizada pela Companhia Riograndense de Turismo em 1974. 
FIGURA 9. INFRA-ESTRUTURA BÁSICA A SER CONSIDERADA PELO ZEE

\begin{tabular}{|c|c|}
\hline \multicolumn{2}{|c|}{ INFRA-ESTRUTURA BÁSICA } \\
\hline Serviços Urbanos & $\begin{array}{ll}\text { - } & \text { Energia e iluminação pública } \\
\text { - } & \text { Limpeza pública } \\
\text { - } & \text { Abastecimento }\end{array}$ \\
\hline Saneamento Básico (Ambiental) & - Coleta e disposição de esgotos \\
\hline Aspectos Demográficos & $\begin{array}{ll}\text { - } & \text { Crescimento demográfico } \\
\text { - } & \text { Densidade demográfica } \\
\text { - } & \text { Distribuição populacional }\end{array}$ \\
\hline Infra-estrutura de Acesso & $\begin{array}{l}\text { - } \quad \text { Sistema rodoviário (estadual/ federal/ veículos } \\
\text { licenciados/ trafego) } \\
\text { - } \quad \text { Sistema ferroviário } \\
\text { - } \quad \text { Sistema aeroviário } \\
\text { - } \quad \text { Sistema hidroviário (interno e terminais } \\
\text { portuários) }\end{array}$ \\
\hline Fatores Econômicos e Financeiros & $\begin{array}{ll}\text { - } & \text { Renda } \\
\text { - } & \text { Política orçamentária }\end{array}$ \\
\hline Aspectos Sociais - Educação & - $\quad$ Escolaridade \\
\hline Aspectos Sociais - Saúde & - Hospitais \\
\hline Aspectos Sociais & - $\quad$ Habitação \\
\hline Sistema de Segurança & $\begin{array}{ll}\text { - } & \text { Delegacias } \\
\text { - } & \text { Postos de Polícia Rodoviária } \\
\text { - } & \text { Bombeiros }\end{array}$ \\
\hline
\end{tabular}

Para ajudar a construir o modelo referencial do turismo sustentável, no que tange a questão da infra-estrutura para a atividade turística, foi feita uma adaptação do Modelo Referencial da Infra-estrutura com as demandas de infra-estrutura acima apresentados. A seguir, é mostrado o modelo referencial de infra-estrutura a ser contemplado no modelo referencial do turismo sustentável (Figura 10):

FIGURA 10 - MODELO DE INFRA-ESTRUTURA BÁSICA PARA O ZEE

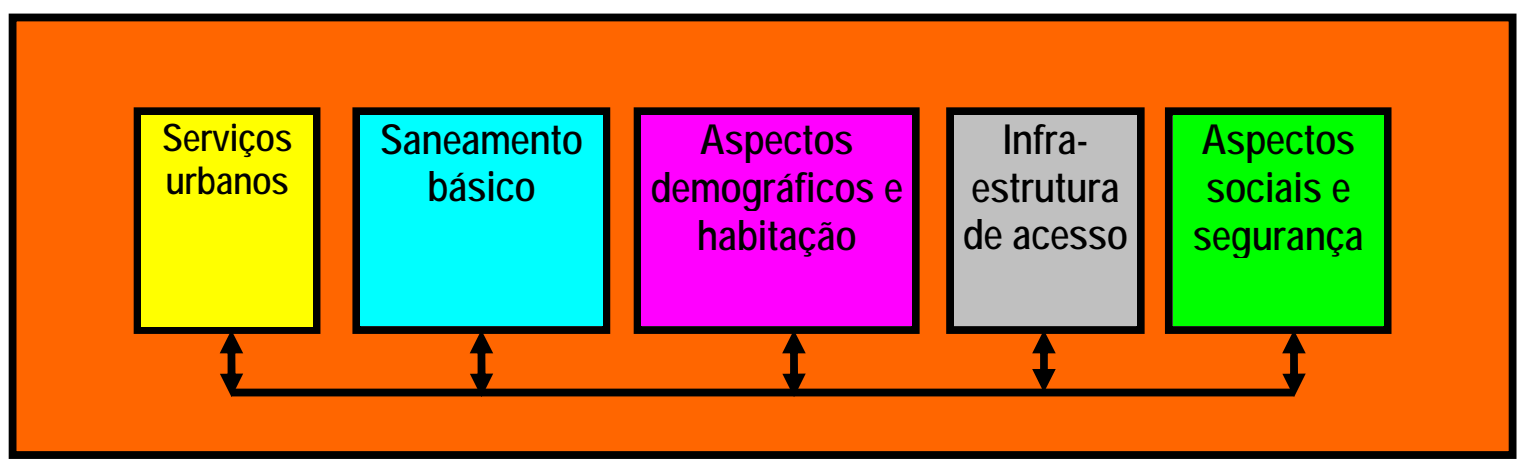


A partir desta compilação, a infra-estrutura pode ser aplicada sobre as unidades territoriais do ZEE, resultando no ordenamento territorial da infra-estrutura facilitando o planejamento das atividades que demandam estas informações.

\subsubsection{Dimensões do ambiente natural e humano dentro do ZEE}

Dentro do Modelo Referencial do Turismo, outro item, adaptado para o ZEE, foi o Conjunto das Relações Ambientais. No modelo existem quatro conjuntos: o primeiro é o Ecológico, o segundo Social, o terceiro Cultural e o quarto Econômico.

A partir de uma adaptação do Modelo Referencial do Turismo, e considerando a metodologia desenvolvida por VERÍSSIMO (2003) - o marco referencial, as premissas e as demandas temáticas e metodológicas do ZEE - , esse modelo passa a ser construído considerando as seguintes dimensões: ecológica, social, cultural, econômica, política, legal e institucional.

A definição dessas dimensões leva em conta a necessidade de integração entre a organização funcional do território, que muda conforme muda a sociedade, com as unidades ambientais, que são as células básicas físico-biótica de informação do ZEE. Sendo assim, para haver o denominador comum é preciso inserir as mesmas dimensões naturais e humanos nas unidades territoriais e ambientais (Figura 11).

FIGURA 11 - DIMENSÕES DOS AMBIENTES NATURAL E HUMANO DO TURISMO A SEREM CONSIDERADOS PELO ZEE

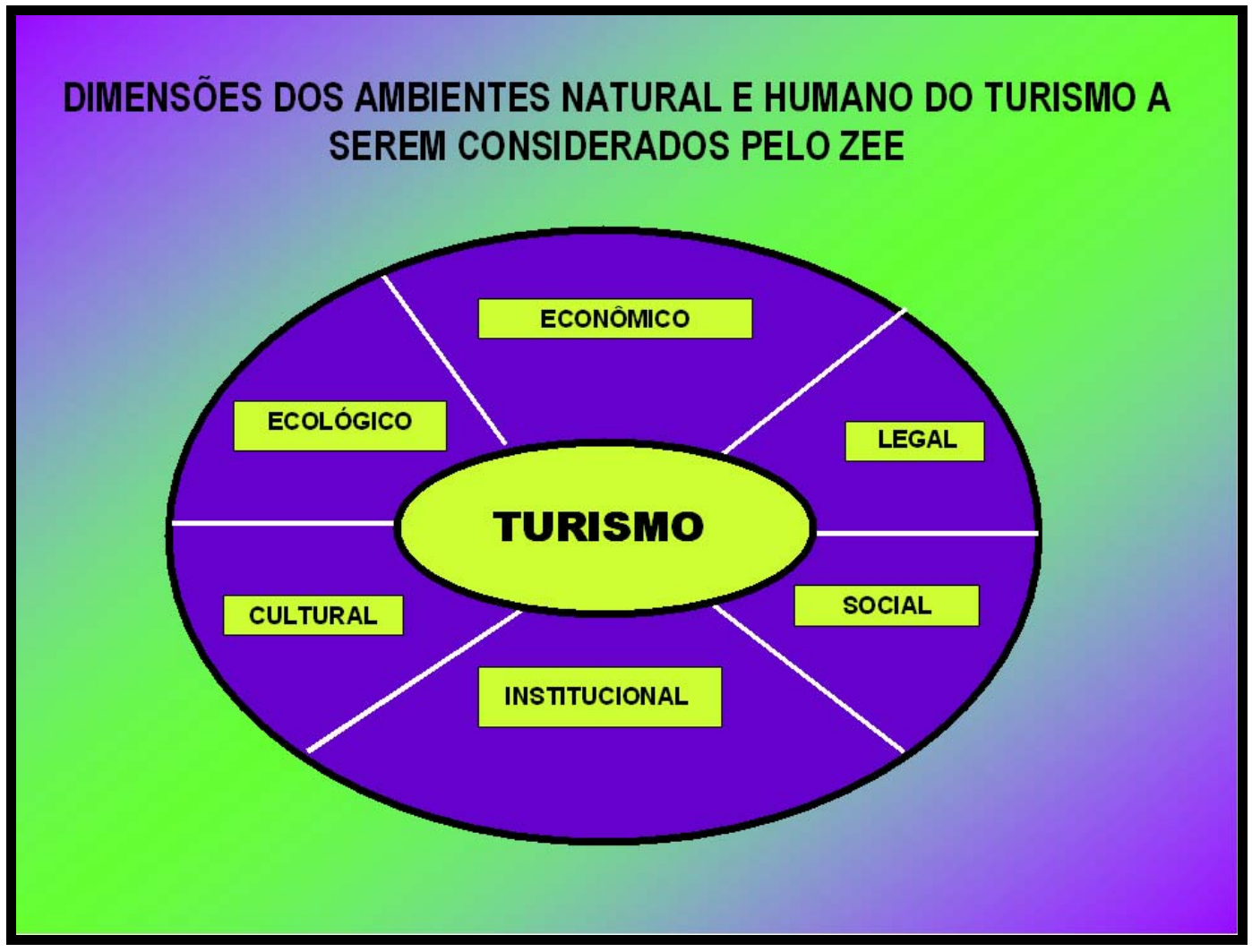




\subsubsection{Modelo de ação para viabilizar turismo sustentável dentro do ZEE}

Outra questão a ser considerada para elaborar o Modelo Referencial para Turismo Sustentável dentro do ZEE diz respeito à necessidade de haver uma coordenação institucional para superar a fragmentação no contexto do processo de planejamento e formulação de políticas públicas. É necessário haver uma articulação para tratar problemas referentes ao ordenamento territorial e ao processo de análise dos impactos ambientais e/ou os efeitos das políticas, planos e programas estabelecidos em determinado contexto (nacional, regional, local ou setorial). Deve ficar claro que o principal objetivo do instrumento ZEE é desenvolver um processo de avaliação do uso do território e dos sistemas naturais. O ZEE não visa coordenar o processo de tomada de decisão para integrar os domínios econômicos, sociais e ambientais, de forma a evitar inconsistências e conflitos entre objetivos, metas e atores participantes do ordenamento territorial e da proteção dos sistemas naturais. Esse processo de coordenação deve existir e para tal é cada vez mais utilizado o instrumento denominado Avaliação Ambiental Estratégica (AAE) . Ou seja, o ZEE é o instrumento técnico e o AAE o instrumento político-institucional.

A falta desses instrumentos é bem clara para a atividade do Turismo. É impossível discutir política, plano ou programa para o setor sem ligá-los ao território onde serão implantados, e também ao contexto político e ideológico onde foram concebidos e aprovados. O mesmo argumento é verdadeiro para a dimensão geográfica, uma vez que é impossível considerar o uso de um determinado território sem ponderar a atividade turística.

A partir do exposto, é apresentado abaixo, modelo de ação para viabilizar turismo sustentável dentro do ZEE (Figura 12). 


\section{MODELO DE AÇÃO PARA VIABILIZAR TURISMO SUSTENTAVEL DENTRO DO ZEE} DESCRIÇÃO DAS INSTITUIÇÕES E CONTEXTO DE DECISÃO: INTEGRAÇÃO VERTICAL DOS NIVEIS DE PLANEJAMENTO E POLITICAS PÜBLICAS

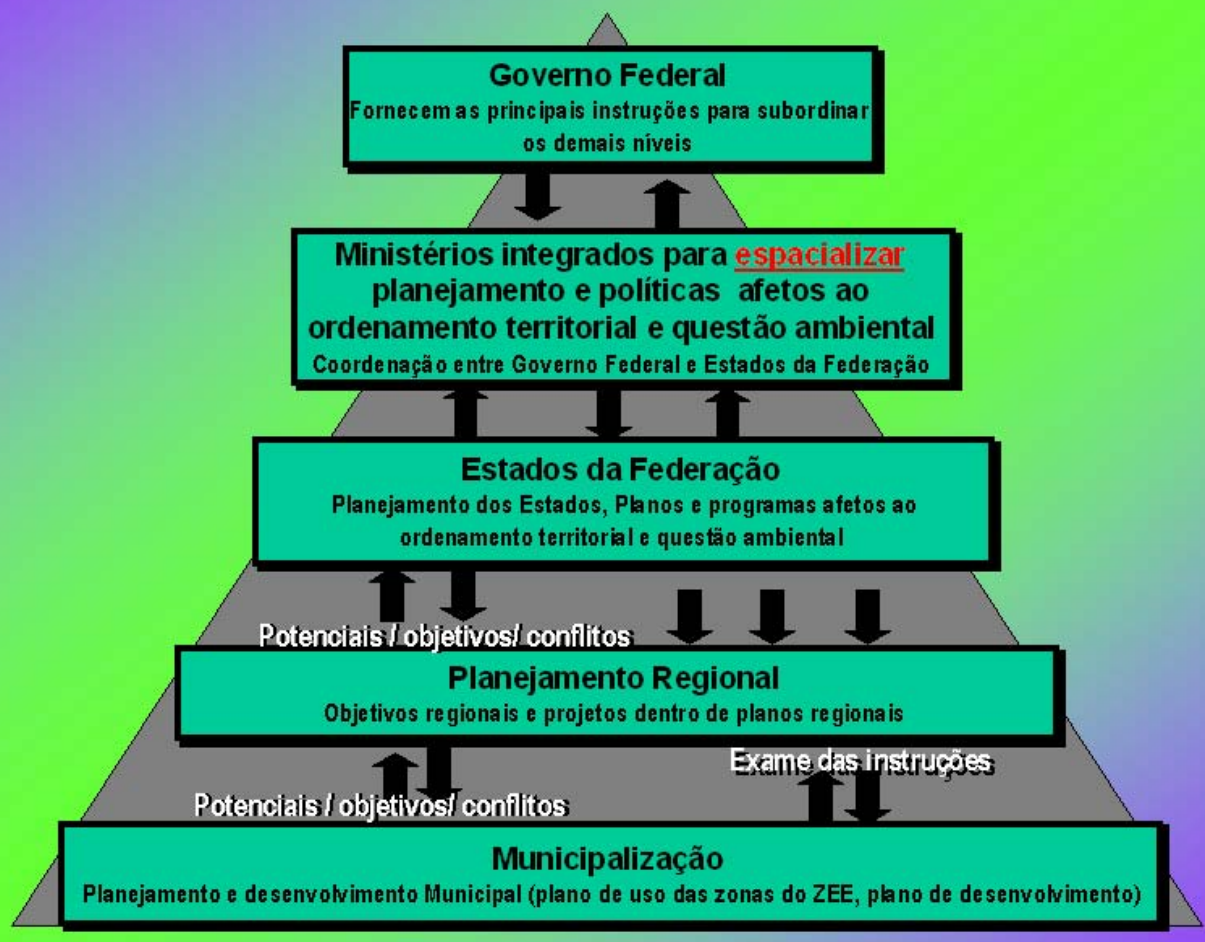

\subsubsection{Modelo de integração das unidades territoriais e ambientais para viabilizar turismo sustentável dentro do ZEE}

Dentro dos trabalhos de Zoneamento Ambiental, um dos pontos chaves é definir as células básicas de informação. Essas células são "espaços homogêneos gráficos", em geral denominados unidades ambientais, ou unidades territoriais, e mais recentemente, de unidades dos sistemas ambientais naturais ${ }^{26}$. Não existe um padrão de unidade ambiental ou territorial utilizado nos ZEE's no Brasil. Até pouco tempo, havia apenas recomendação para que a unidade fosse escolhida de acordo com critérios próprios que podiam ir desde condições naturais até propósitos político-administrativos. No momento, a equipe do ZEE Brasil não definiu qual será a célula básica de informação a ser utilizada nos Zoneamentos Ambientais.

${ }^{26}$ MINISTÉRIO DO MEIO AMBIENTE. Secretaria de políticas para o desenvolvimento sustentável. PROGRAMA ZONEAMENTO ECOLÓGICO ECONÔMICO. Diretrizes metodológicas para o Zoneamento Ecológico-Econômico no Brasil. Brasília: MMA/SDS, 2001. 101p. 
No caso específico deste trabalho, a partir do modelo referencial, das premissas, das temáticas e metodologias requeridas para o ZEE e das especificidades da atividade turística, assume-se que todas as células básicas de informação sejam elas ambientais ou territoriais, têm sua importância, posto que suas propriedades essenciais, ou "sistêmicas", são propriedades do todo. Acresce o fato do desenvolvimento sustentável, bem como os princípios das integridades ecológico e cultural não devem ser tratados apenas dentro de uma única célula básica de informação. Caso isso ocorra, são perdidas todas as possibilidades de formulação de indicadores, com destaque para a atividade de Turismo, uma vez que a diversidade destes descritores está ligada a célula básica de informação selecionada no ZEE (Figura 13).

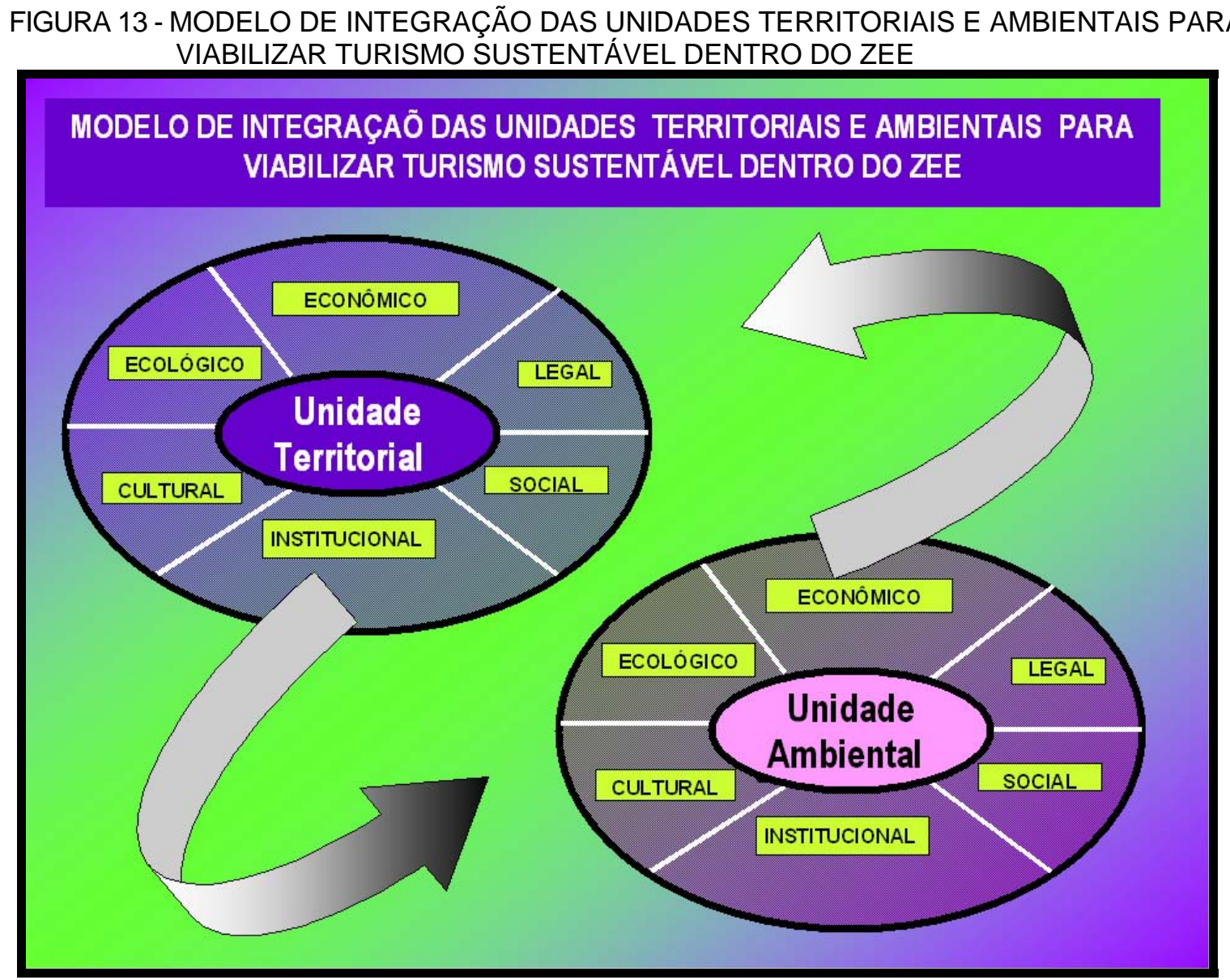

Contudo, é importante mencionar que as bacias hidrográficas e os municípios são as unidades que apresentam uma ligação mais direta com a atividade turística, que é mais setorial. As demais, apesar de apresentarem ligação e estarem integradas, ainda são informações pouco compreendidas e assimiladas dentro do planejamento e das políticas de turismo. 


\section{CONCLUSÃO}

Este trabalho buscou contribuir para ampliar o processo de integração do planejamento, formulação de políticas públicas e articulações político-institucionais, focalizando a análise do instrumento de ordenamento territorial ZEE integrado à atividade turística sustentável.

Analisando a origem, finalidades e características do instrumento ZEE, bem como as demandas temáticas e metodológicas dos estados brasileiros resultantes dos workshops relativos aos "Dez anos do Programa ZEE", conclui-se que os avanços propostos apresentam uma forte relação com o turismo, sendo seus resultados bastante significativos. Porém, é preciso integrar políticas públicas, utilizar unidades territoriais e ambientais e tratar as questões urbanas, rurais e de manutenção dos sistemas naturais de forma integrada quando se pretende utilizar o ZEE tendo em vista o turismo sustentável.

Ainda, foi constatado que entre os motivos pelos quais o instrumento ZEE tem sido pouco utilizado estão nos problemas dos quais a SDS tentou solucionar com os workshops e com a publicação do documento "Diretrizes metodológicas para o Zoneamento Ecológico Econômico no Brasil“. Porém, estas ações não sanaram a necessidade de uma padronização do ZEE, possibilitando a criação de um instrumento efetivo de avaliação do uso do território e dos sistemas naturais, que auxilie o planejamento. Os resultados obtidos através da análise de técnicos e acadêmicos não oferecem aplicabilidade para gestores e planejadores (principalmente locais) devido a difícil compreensão e aplicabilidade dos resultados para leigos e autodidatas.

A inovação na adoção do Zoneamento Ecológico-Econômico é a relação direta com diversos instrumentos oficiais já constituídos, concentrando em si informações e análises demandadas por todos eles, em maior ou menor profundidade que, unidas em um só documento, tomadas em conjunto, proporcionam uma maior compreensão de todas as dinâmicas territoriais de desenvolvimento, sanando as dificuldades técnicas resultantes do ordenamento e sistematização do grande volume de dados coletados de forma dispersa.

Apresentando o panorama do Turismo no Brasil com enfoque no seu planejamento, nas suas políticas públicas e nos equívocos de implementação dessa atividade em termos de ordenamento territorial, chegou-se a conclusão de que as políticas de turismo devem estar relacionadas a outras políticas de âmbito federal, regional, estadual e municipal. Atualmente o tema turismo tem sido tratado por estas 
instituições com falta de clareza e abordagem reduzida, não sendo trabalhado em sua complexidade, limitado a aspectos parciais. Este tratamento "superficial" provoca uma repercussão negativa para o setor, pois as políticas são estabelecidas em outras escalas de gestão (regional, estadual e municipal), sem referência a uma política nacional, o que reforça a dificuldade de integração de políticas e planos de turismo entre si, e com outras políticas setoriais. Neste sentido, uma verticalização das instituições e suas competências se mostram prioritário.

Verificando as ações direcionadas à questão ambiental e de ordenamento territorial do turismo, conclui-se que até meados da década de 1990, apesar de existir ênfase no aproveitamento dos recursos naturais do país e no (re)ordenamento do território para uso turístico, a política nacional de turismo reduz-se na prática, à ampliação e melhoria da infra-estrutura.

Fazendo uma abordagem do Modelo Referencial do Turismo no que concerne à infra-estrutura básica e o conjunto das relações ambientais da atividade é importante destacar que ambos, ao serem trabalhados e tomados como modelo referencial, devem ser ampliados, quando se trata o ZEE.

Outra questão analisada foi à confusão generalizada no tratamento de infraestrutura urbana e infra-estrutura do turismo. Não se deve confundir uma com a outra. Deve-se entender que a infra-estrutura turística abarca mais itens do que a infraestrutura urbana, pois depende de outras questões que não estão situadas no que compete aos centros urbanos.

A construção de diretrizes para um Modelo Referencial do Turismo Sustentável para ZEE considerou os princípios básicos que norteiam as metodologias de Zoneamento, as Diretrizes metodológicas para ZEE do MMA/SDS ${ }^{27}$, as lacunas temáticas e metodológicas dos workshops nacional e regionais sobre o ZEE ocorridos, uma tese de doutorado em metodologia de Zoneamento Ambiental ${ }^{28}$ e o referencial teórico do turismo. Neste sentido chegou-se a conclusão de que os avanços propostos em relação às temáticas e metodologias de ZEE estão muito relacionados com o turismo e apresentam resultados significativos para a atividade. No entanto, para essa associação ser viável é preciso integrar as políticas públicas, utilizar simultaneamente as unidades territoriais e ambientais do ZEE, dar um tratamento integrado às questões urbanas, rurais e

${ }^{27}$ MINISTÉRIO DO MEIO AMBIENTE. Secretaria de políticas para o desenvolvimento sustentável. PROGRAMA ZONEAMENTO ECOLÓGICO ECONÔMICO. Diretrizes metodológicas para o Zoneamento Ecológico-Econômico no Brasil. Brasília: MMA/SDS, 2001. 101p.

${ }^{28}$ Veríssimo, op. cit 
manutenção dos sistemas naturais, tendo como marcos referenciais 0 desenvolvimento sustentável, a visão sistêmica, a integridade ecológica e cultural e a participação.

E finalmente, trabalhou-se sobre um modelo referencial do turismo para elaborar um modelo referencial para o turismo sustentável dentro do ZEE, utilizando o Conjunto da Organização Estrutural e o Conjunto das Relações Ambientais inserindo o planejamento turístico no Brasil no contexto do instrumento ZEE. Tendo em vista que o conjunto das Relações Ambientais apresentado por Mário BENI (2001) não considera algumas dimensões, estas foram inseridas no contexto do modelo buscando garantir a integridade e sustentabilidade do sistema.

Deste estudo resultou que a Análise Ambiental Estratégica viria como proposição de uma coordenação institucional para superar a fragmentação do processo de planejamento e formulação de políticas públicas no Brasil (principalmente no que diz respeito ao Turismo). Neste sentido, conclui-se que todos as diretrizes apresentadas para construir um modelo referencial sustentável de turismo para o ZEE acontecerão quando houver uma verticalização das instituições. Espera-se com este trabalho, que as instituições que planejam o turismo no Brasil venham encontrar contribuições para o despertar da integração nacional. 


\section{REFERÊNCIAS}

BECKER, B., EGLER, C. Brasil, uma potencia regional na economia do mundo. 2. ed. Rio de Janeiro: Bertrand, 1995.

BECKER, B. Políticas e planejamento do turismo no Brasil. In: YÁZIGI, Eduardo et all. (Orgs.). Turismo, Espaço, Paisagem e Cultura. São Paulo: Hucitec. 1996. 181193pp.

BENI, M. C. Política e Estratégia do desenvolvimento regional: planejamento integrado e sustentável do turismo, Turismo em Análise, São Paulo, Vol.10, N. 1, pp. 7- 17, 1999.

BENI, M. C. Política e estratégia do desenvolvimento regional: roteiro metodológico com base na instrumentação e operacionalização do SISTUR (Sistema de Turismo aplicado ao projeto costa oeste-Estudo de caso), Turismo: visão e ação, Itajaí, Ano 2, No. 3.pp, 51-70, 1999.

BENI, M. C. Análise Estrutural do Turismo. 2. ed. São Paulo: SENAC, 2001.

BRASIL. Decreto $n^{\circ} 4.297$, de 10 de julho de 2002. Regulamenta o art. $9^{\circ}$, inciso II, da Lei $n^{0} 6.938$, de 31 de agosto de 1981, estabelecendo critérios para o Zoneamento Ecológico-Econômico do Brasil - ZEE, e dá outras providências. Diário Oficial da Republica Federativa do Brasil, Brasília,11.7.2002.

BRASIL. Decreto $\mathrm{n}^{0}$ 99.540, de 21 de setembro de 1990. Institui a Comissão Coordenadora do Zoneamento Ecológico-Econômico do Território Nacional e dá outras providências. Diário Oficial da Republica Federativa do Brasil, Brasília, 24.9.90.

BRASIL.. Decreto Lei n.55, de 18 de novembro de 1966. Define a Política Nacional de Turismo (PNT), cria o Conselho Nacional de Turismo (CNTur) e a Empresa Brasileira de Turismo (EMBRATUR) Diário Oficial da Republica Federativa do Brasil, Brasília, 18.11.66.

BRASIL. Lei no 6.938, de 31 de agosto de 1981. Dispõe sobre a Política Nacional do Meio Ambiente, seus fins e mecanismos de formulação e aplicação, e dá outras providências. Diário Oficial da Republica Federativa do Brasil, Brasília, 2.9.81

BRASIL. Ministério da Indústria Comércio e Turismo. Política Nacional de Turismo. Diretrizes e Programas. Brasília, 1996-1999. 
BRASIL. Ministério do Meio Ambiente. Secretaria de políticas para o desenvolvimento sustentável. Programa Zoneamento Ecológico Econômico diretrizes metodológicas para o zoneamento ecológico econômico no Brasil. Brasília: MMA/SDS, 2001. 101p.

BRASIL. Ministério do Turismo. Inventário da Oferta Turística - Metodologia. Brasília, 2003.

CRUZ, R. de C. Políticas de turismo e território. 3. ed. São Paulo: Contexto, 2002.

EMBRATUR. O Turismo na Economia Nacional: a revolução silenciosa. Brasília, 1999.

FERRAZ, J. A. Regime Jurídico do Turismo. Campinas: Papirus, 1992. 162 p.

GRAU, E. R. Direito Urbano: regiões metropolitanas, solo criado, zoneamento e controle ambiental. São Paulo: Revista dos Tribunais, 1983.

MOLINA \& RODRÍGUEZ, S. Planejamento integral do Turismo: um enfoque para a América Latina. São Paulo: Editora: Educs, 2001.

OFICINA DE PLANEJAMENTO "Agenda Ambiental para o Turismo". Relatório Técnico Mtur MMA. Brasília, 2004.

ORGANIZAÇÃO MUNDIAL DE TURISMO. 1999. Agenda para planejadores locais: turismo sustentável e gestão municipal. Bruxelas, 2001.

PETROCCHI, M. Turismo, Planejamento e Gestão. São Paulo: Futura, 1998.

PINTO, A. C. B. Turismo e Meio Ambiente: Aspectos jurídicos. Campinas: Papirus, 1998.

PLANTUR. PLANO NACIONAL DE TURISMO 1992-1994. EMBRATUR. Instituto Brasileiro de Turismo. Brasília, 1992.

ROTEIROS DO BRASIL. Programa de Regionalização do Turismo. PROGRAMA DE REGIONALIZAÇÃO DO TURISMO Diretrizes Politicas. Brasília, 2004. 
